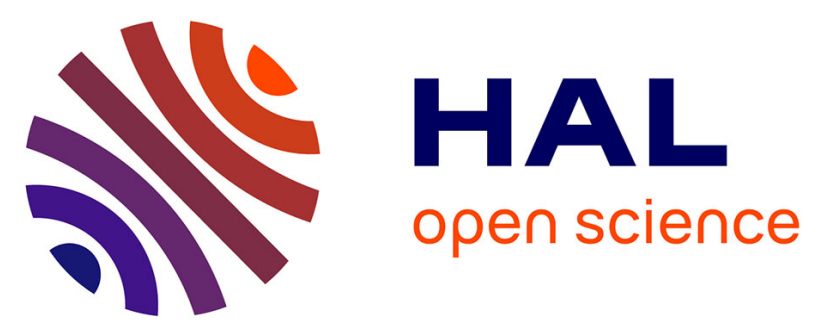

\title{
Current Sensors Fault Detection and Tolerant Control Strategy for Three-Phase Induction Motor Drives
}

Younes Azzoug, Mohamed Sahraoui, Remus Pusca, Tarek Ameid, Raphaël Romary, Antonio J Marques Cardoso

\section{- To cite this version:}

Younes Azzoug, Mohamed Sahraoui, Remus Pusca, Tarek Ameid, Raphaël Romary, et al.. Current Sensors Fault Detection and Tolerant Control Strategy for Three-Phase Induction Motor Drives. Electrical Engineering, 2021, 103 (2), pp.881-898. 10.1007/s00202-020-01120-5 . hal-03256276

\section{HAL Id: hal-03256276 \\ https://hal-univ-artois.archives-ouvertes.fr/hal-03256276}

Submitted on 10 Jun 2021

HAL is a multi-disciplinary open access archive for the deposit and dissemination of scientific research documents, whether they are published or not. The documents may come from teaching and research institutions in France or abroad, or from public or private research centers.
L'archive ouverte pluridisciplinaire HAL, est destinée au dépôt et à la diffusion de documents scientifiques de niveau recherche, publiés ou non, émanant des établissements d'enseignement et de recherche français ou étrangers, des laboratoires publics ou privés. 


\title{
Current Sensors Fault Detection and Tolerant Control Strategy for Three-Phase Induction Motor Drives
}

\author{
Younes Azzoug a, b,*, Mohamed Sahraoui ${ }^{\mathrm{a}, \mathrm{c}}$, Remus Pusca ${ }^{\mathrm{b}}$, Tarek Ameid ${ }^{\mathrm{b}}$, Raphaël Romary ${ }^{\mathrm{b}}$, \\ Antonio J. Marques Cardoso ${ }^{\mathrm{c}}$ \\ ${ }^{a}$ LGEB, University of Biskra, Algeria. \\ ${ }^{\mathrm{b}}$ Univ. Artois, UR 4025 LSEE, Bethune, F-62400, France. \\ ${ }^{c}$ CISE - Electromechatronic Systems Research Centre, University of Beira Interior, Covilhã, Portugal..
}

\section{Acknowledgments}

This work has been achieved within the framework of CE2I project (Convertisseur d'Energie Intégré Intelligent). CE2I is co-financed by European Union with the financial support of the European Regional Development Fund (ERDF), French State and the French Region of Hauts-de-France.

As well, this work was supported by the European Regional Development Fund (ERDF) through the Operational Programme for Competitiveness and Internationalization (COMPETE 2020), under Project POCI-01-0145-FEDER-029494, by National Funds through the FCT - Portuguese Foundation for Science and Technology, under Projects PTDC/EEIEEE/29494/2017, UIDB/04131/2020, and UIDP/04131/2020. 


\title{
Current Sensors Fault Detection and Tolerant Control Strategy for Three-Phase Induction Motor Drives
}

\begin{abstract}
In the case of failure of one or more components of a drive system, the emergency shutdown of the system is not always the best way to act. Therefore, simultaneous reconfiguration of the drive control strategy is mandatory to enable an uninterrupted operation to cater for the catastrophic failure. In this context, this paper presents a current sensors fault-tolerant control method for induction motor drives, based on vector control and currents estimation. Several important issues are considered in the proposed method, namely, the detection of sensors failure, isolation of the faulty sensors, and reconfiguration of the control system by proper currents estimation. A new adaptation of the Luenberger observer is proposed and used to perform the task of stator currents estimation. Furthermore, a developed logic circuit is used to detect the faulty current sensors and isolate them with simultaneous generation of logic impulses allowing switching to a proper estimation. The proposed faulttolerant control strategy is firstly tested in MATLAB/Simulink environment in order to illustrate its high-performance. Then, several experimental tests are carried out on a $1.1 \mathrm{~kW}$ three-phase induction motor to validate the theoretical results and to confirm the effectiveness of the proposed algorithm.
\end{abstract}

Keywords: Fault-tolerant control; fault detection; current sensor; current estimation; induction motor; vector control.

\section{Introduction}

The Induction Motor (IM) is the most widely used machine for several demanding applications in industry due to its good performance, simple construction, reduced size, excellent reliability, a wide range of operating speeds, and especially due to its low-cost. The concept of vector control introduced by Blaschke [1] and the development of power electronic semiconductors were the key factors to this widespread use of induction motors and the revolution of Variable Speed Drives (VSDs) [2]. It is well known that natural independence between flux creation and torque production is clearly the fundamental property of a separate excitation DC machine. Thus, the aim of Field Oriented Control (FOC) of induction motors is to reproduce the quadrature between current components and flux vectors, which gives high-performance drive applications and makes FOC as an industry standard.

Usually, a variable speed drive includes two major circuits: power converter circuit and control unit; these latter includes sensors, regulators, and control algorithms. It is estimated that faults in the control unit are responsible for more than $53 \%$ of breakdowns in adjustable speed drives [3-5] (Fig. 1).

Generally, a variable speed induction motor drive needs feedback information from a speed/position transducer, two or three current sensors, and a DC-link voltage sensor at least $[6,7]$. Unfortunately, current sensors are very prone to failures such as connection problems [8], noise, offset, and positive or negative gain, caused by defects in the core of the sensor (corrosion, cracks, residual magnetic fields and core breakage), changes in the magnetic characteristics of the ferrite core due to temperature variations, changes in the orientation of the magnetic field induced in the sensor (due to mechanical shocks or other reasons) [9], operating environment, etc. All these defects can lead to catastrophic drive failures or significant performance degradation. In this context and for many industrial critical applications such as, high-power wind energy production systems [10, 11], aerospace applications [12, 13], electrical vehicles, and traction drives $[14,15]$, the reliability, service continuity, and safety of electrical drive systems are basic necessity. Therefore, it is important to detect and isolate any kind of fault at the time of their occurrence. This should be performed by developing integrated Fault Detection and Isolation (FDI) algorithms, and employ sensor FaultTolerant Control (FTC) methods to avoid unexpected shutdowns and maintain a minimum level of performance.

Recently, considerable attention has been paid to faulttolerant control techniques, which became a very active and attractive research field. In the literature, one can find two types of FTC: active and passive FTC. The first one reacts to system component failures in an "active" manner, by reconfiguration within the same system of control through Fault Detection, Isolation and Reconfiguration (FDIR) mechanisms, in order to provide the appropriate faulttolerant signal $[16,17]$, maintain the stability and acceptable performance of the entire system. The second one is the passive FTC; this type of controller is designed to be robust against failures and uncertainties. Therefore, when a failure occurs, the controller should be able to maintain the system stability with acceptable performance degradation [18]. Contrary to active FTC, passive FTC does not require FDIR circuits [19]. Besides, passive FTC techniques are not commonly used for sensors fault tolerance, but they are widely used for intern-turn short circuits fault tolerance [20, 21] and open circuit phase fault [22-24].

Several studies have been published in recent years documenting active FTC methods for VSDs to solve the problems caused by sensor failures. One of the first examples of FTC for electrical drives was presented in [6], where the authors have proposed an FDI method based on redundancies in a temporal window using the parity space approach. The study reported in [25] suggests a sensor's FDIR mechanism for IM drives based on extended Kalman filter and a reduced number of adaptive observers to keep a continuous system operation even with speed, DC-link voltage, and current sensor failures. In [26], an FTC technique against failures in speed sensor and current sensors for IM drives is proposed, which is implemented through three adaptive observers with different inputs, three current sensors, and dc-link voltage sensor. However, this 
method is not suitable to achieve an efficient FTC in case of failures in two or three sensors, where it can operate in speed sensorless mode in the case of speed sensor failure or with speed sensor, two current sensors, and dc-link voltage sensor in the case of one of the current sensors is faulty. This method has been improved by the same author, where in [27] only two current sensors have been employed contrary to [26]. Moreover, the improvements in [27] make this method able to operate with a single current sensor in addition to the dc-link voltage sensor, but the number of the used adaptive observers is still three. Another FDIR mechanism for current sensors faults in permanent magnet synchronous motor drives is described in [28], in which stator currents are recovered using two adaptive observers and where the faulty sensor is detected through a builtin logic algorithm. In [10], a current sensor FTC for a wind energy conversion system with a doubly-fed induction generator is presented. This technique is based on a predictive model to reconstruct the stator currents, where the FDIR mechanism contains four parts: residual generation, fault detection, fault memorization, and fault identification. However, all these parts make the implementation very difficult. A fault-tolerant operation of induction motor drives with an automatic controller reconfiguration is described in [29]. Four different controllers are used in this method: Indirect Rotor Field Oriented Control (IRFOC) to overcome faults caused by the voltage sensor, speed sensorless vector control to compensate for interruptions coming from the speed sensor breakdown, scalar current magnitude control to overcom failures provoked by abnormal functioning of current sensors, and open-loop control in case where no sensor is operating correctly. A smooth FTC of IM drives with sensor failures is presented in $[30,31]$. Comparing to the method mentioned previously, the authors have successfully reduced the number of controllers from four to three, using direct torque control, IRFOC, and volt/hertz (V/f) control. The proposed FTC in [32] includes two standard controllers (vector control with $\mathrm{V} / \mathrm{f}$ control) and a bank of observers. If a failure occurs in one current sensor, the vector control is maintained by replacing faulty data with the estimated ones obtained from the observer bank. In case of failure of two current sensors, the V/f strategy is selected to ensure that the IM drive operates within the limits, keeping a minimum of performance. The method of multi-controllers is adopted also in $[14,15,33,34]$ but the major drawback of this method, as mentioned in [34], is that some of these techniques are experimentally difficult to implement. In [35], a stator current sensor FDI strategy for direct fieldoriented control of an IM drive is proposed. The influence of stator current sensor faults on the control system performance is investigated. Indeed, a logic-based circuit is designed to identify the faulty sensor and replace it by an appropriate stator current, calculated starting from algebraic relations and other healthy currents. Nevertheless, this approach is not practical when successive faults appear in the different sensors. The same method is presented in [36] but with an FDI mechanism based on the artificial neural network approach. Recently, an interesting approach for this issue has been presented in [37, 38]. The current sensors FTC scheme for a direct torque controlled induction motor has been discussed, the detection of the faulty sensor is completed by a third-difference operator applied to each phase of the IM [39], while a flux-linkage observer performs the task of stator currents estimation. Moreover, the isolation and reconfiguration of the control system are accomplished by a logic circuit. In [40], the same authors develop the same idea with a different controller. However, obtaining high-performance current fault detection by the third-difference operator requires special attention to the threshold value when the low-pass filter cut-off frequency is lower than half of the sampling frequency [40].

In the literature of $\mathrm{AC}$ drives without current sensors, a speed control technique with a single dc-link current sensor for a Permanent Magnet Synchronous Motor (PMSM) used to drive the air-conditioning compressor of an electric vehicle is proposed in $[41,42]$. However, this method cannot be achieved with a standard Pulse Width Modulation (PWM), due to the fact of the active voltage shorter duration time, which needs an adjusted PWM. This method is used also for permanent magnet AC servo systems associated with a sliding mode observer for rotor position estimation [43]. Another single current sensor method for PMSM and IM three-phase current reconstruction is described in [4447]. This method is realized with a current sensor and a shunt resistor in the dc-link of the VSI.

The present paper includes several important features that are distinct from other already proposed approaches:

- In the proposed method only one observer is used to generate the three-phase stator currents, whilst in the presented literature review, most of them use two or three observers to estimate the line currents.

- The proposed method is suitable to achieve fault detection, isolation, and reconfiguration when two or three current sensors are interrupted successively. Thus, the system can operate with the required performance without any current sensor.

- This technique can be adaptively reorganized in the event of recovering the faulty sensors. This allows maintaining the maximum performance of the control system considering the complementary nature of the other sensors.

- Three different sensor failures are considered: complete sensor outage, gain drop, and the start-up with offset fault that hasn't been addressed in the literature review, in order to validate the estimation and fault detection accuracy.

A table is presented in Appendix $\mathrm{C}$ in order to summarize the comparison of the suggested technique with the other methods in the literature as well as clarifying some advantages and disadvantages of each one.

All the above-mentioned features are extensively tested in Matlab/Simulink environment and validated on an experimental test bench.

This paper is organized into six sections. Section II presents the induction motor model and his vector control. Section III analyses the theory and the design of the proposed fault-tolerant control against current sensor failures. Simulation results are presented in section IV. Afterward, section $\mathrm{V}$ discusses the experimental results. Finally, section VI presents the main conclusions of the paper. 


\section{Induction motor vector control}

The vector control continues to be the main drive strategy used in industrial applications due to its simplicity and fast response to the changes in operating conditions. Indeed, the Indirect Rotor Field Oriented Control (IRFOC) strategy has been extensively used in several suggested current sensors FTC schemes because it involves a minimum of calculations, and requires fewer PI controllers. In addition to its simplicity of implementation, IRFOCbased drives can be adjusted easily. The basic scheme of IRFOC for IM drives is presented in Fig. 2, in which three current sensors (in phase-a, phase-b, and phase-c), a speed incremental encoder, and a voltage sensor in the DC-link are used.

\subsection{Induction motor model}

Among the various models used to represent the induction motor, the one that will be exploited in this paper uses a reference frame $(d, q)$ linked to the rotating field, and takes the stator currents, the rotor fluxes, and the rotational speed as state variables. This model is expressed by the following system of equations, using the voltages as control variables:

$$
\begin{gathered}
\frac{d}{d t} I_{s d}=-\lambda I_{s d}+\omega_{s} I_{s q}+\frac{\gamma_{s}}{\tau_{r}} \varphi_{r d}+\gamma_{s} \omega_{r} \varphi_{r q} \\
+\frac{1}{\kappa L_{s}} V_{s d} \\
\frac{d}{d t} I_{s q}=-\omega_{s} I_{s d}-\lambda I_{s q}-\omega_{r} \gamma_{s} \varphi_{r d}+\frac{\gamma_{s}}{\tau_{r}} \varphi_{r q} \\
\quad+\frac{1}{\kappa L_{s}} V_{s q} \\
\frac{d}{d t} \varphi_{r d}=\frac{M}{\tau_{r}} I_{s d}-\frac{1}{\tau_{r}} \varphi_{r d}+\left(\omega_{s}-\omega_{r}\right) \varphi_{r q} \\
\frac{d}{d t} \varphi_{r q}=\frac{M}{\tau_{r}} I_{s q}-\left(\omega_{s}-\omega_{r}\right) \varphi_{r d}-\frac{1}{\tau_{r}} \varphi_{r q} \\
\frac{M}{T}=p \frac{M}{L_{r}}\left(\varphi_{r d} I_{s q}-\varphi_{r q} I_{s d}\right) \\
\frac{d}{d t} \Omega_{r}=\frac{1}{J}\left(T_{e}-T_{l}\right)-\frac{F}{J} \Omega_{r}
\end{gathered}
$$

where:

$\kappa=1-\frac{M^{2}}{L_{s} L_{r}} \quad \lambda=\frac{R_{s}}{\kappa L_{s}}+\frac{R_{r} M^{2}}{\kappa L_{s} L_{r}^{2}} ; \quad \gamma_{s}=\frac{M}{\kappa L_{s} L_{r}} ;$

$\tau_{s}=\frac{L_{s}}{R_{s}} ; \quad \tau_{r}=\frac{L_{r}}{R_{r}} ; \quad \omega_{r}=\omega_{r} p$

\subsection{Indirect rotor field oriented control}

The IRFOC of induction motors aims at making the control of flux and torque similar to the one of the separately excited DC motor, where these parameters are controlled independently. In this case, the oriented rotor flux implies the following conditions:

$$
\begin{gathered}
\varphi_{r d}=\varphi_{r} \\
\varphi_{r q}=0
\end{gathered}
$$

From Eq. (3), Eq. (5), Eq. (7), and Eq. (8), the flux and the torque expressions become:

$$
\begin{aligned}
& \varphi_{r}=\frac{M}{\tau_{s} s+1} I_{s d} \\
& T_{e}=p \frac{M}{L_{r}} \varphi_{r} I_{s q}
\end{aligned}
$$

The electromagnetic torque depends only on one single current, which is the quadrature stator current $I_{s q}$. Like in DC motors, two independent action variables $\left(I_{s d}, I_{s q}\right)$ are obtained, the first one for adjusting the flux, and the second one for adjusting the torque. So, from Eq. (4) it is obtained:

$\omega_{s}=\frac{M}{\tau_{r} \omega_{r}} I_{s q}+p \Omega_{r}$

From the integral of Eq. (11) it results the angle $\theta_{s}$ which will be used in all transformations.

$\theta_{s}=\int \omega_{s} d t$

\section{Current sensors fault-tolerant control}

The main steps to follow when a fault occurs is to trigger an emergency alarm, then, to identify which fault has been detected, and finally to decide how to deal with it. The basis of a fault-tolerant control is detecting a fault, identifying its location, taking appropriate actions to isolate the faulty material, and reconfiguring the system. Fig. 3 describes the most important stages of the proposed current sensors FDIR scheme of IM drives.

\subsection{Stator currents estimation}

In order to design a high-performance current estimator, with a good compromise between stability and simplicity of the observer, a model of the machine drive is defined in $(\alpha, \beta)$ reference frame can be explained with the following state equations:

$\left\{\begin{array}{l}\dot{X}=A\left(\omega_{r e}\right) X+B U \\ Y=C X\end{array}\right.$

where:

$X=\left[\begin{array}{llll}I_{s \alpha} & I_{s \beta} & \varphi_{r \alpha} & \varphi_{r \beta}\end{array}\right]^{T}$

$Y=\left[\begin{array}{ll}I_{s \alpha} & I_{s \beta}\end{array}\right]^{T}$

$U=\left[\begin{array}{ll}V_{s \alpha} & V_{s \beta}\end{array}\right]^{T}$

and:

$A=\left[\begin{array}{cccc}\eta_{1} & 0 & \eta_{2} & \omega_{r e} \eta_{3} \\ 0 & \eta_{1} & -\omega_{r e} \eta_{3} & \eta_{2} \\ \eta_{4} & 0 & \eta_{5} & -\omega_{r e} \\ 0 & \eta_{4} & \omega_{r e} & \eta_{5}\end{array}\right] ; \quad B=\left[\begin{array}{cc}\frac{1}{\kappa L_{s}} & \frac{1}{\kappa L_{s}} \\ 0 & 0 \\ 0 & 0\end{array}\right] ;$

$C=\left[\begin{array}{llll}1 & 0 & 0 & 0 \\ 0 & 1 & 0 & 0\end{array}\right]$

as well as:

$\eta_{1}=-\left(\frac{1}{\tau_{s} \kappa}+\frac{(1-\kappa)}{\tau_{r} \kappa}\right) ; \quad \eta_{2}=\frac{M}{\kappa L_{s} L_{r} \tau_{r}} ; \quad \eta_{3}=\frac{M}{\kappa L_{s} L_{r}} ;$

$\eta_{4}=\frac{M}{\tau_{r}} ; \quad \eta_{5}=\frac{1}{\tau_{r}}$

The general theory of an adaptive observer $(E q .(14))$ is based on a deterministic model of the system, and an 
adaptive mechanism for the estimated variables, through a gain matrix that ensures the system stability [48, 49]. However, in this work, the proposed idea for stator currents estimation with the Luenberger observer theory is based on the conservation of the state model (Eq. (13)) of the IM with the gain matrix $\mathrm{D}$, which has been determined by the classical pole placement procedure described in [50]. Nevertheless, it is necessary to replace the adaptive mechanism by the measured rotational speed, as well as to feed the observer with the stator voltages provided by the voltage synthesizer. This gives the stator currents estimation, as illustrated in Fig. 4.

The adaptive current observer equations are expressed in $E q$. (2) where the symbol "^" denotes the estimated values:

$\left\{\begin{array}{l}\dot{\hat{X}}=A\left(\omega_{r e}\right) \hat{X}+B U+D \xi \\ \hat{Y}=C \hat{X}\end{array}\right.$

where:

$\hat{X}=\left[\begin{array}{llll}\widehat{I_{s \alpha}} & \widehat{I_{s \beta}} & \widehat{\varphi_{r \alpha}} & \widehat{\varphi_{r \beta}}\end{array}\right]^{T}$

$\widehat{Y}=\left[\begin{array}{ll}\widehat{I_{s \alpha}} & \widehat{I_{s \beta}}\end{array}\right]^{T}$

$\xi=\left[\begin{array}{ll}I_{s \alpha}-\widehat{I_{s \alpha}} & I_{s \beta}-\widehat{I_{s \beta}}\end{array}\right]^{T}$

Since there are no information about the measured currents, the vector $\xi$ becomes:

$\xi=\left[\begin{array}{ll}-\widehat{I_{s \alpha}} & -\widehat{I_{s \beta}}\end{array}\right]^{T}$

The gain matrix $\mathrm{D}$ is defined as follows:

$D=\left[\begin{array}{cccc}D_{1} & D_{2} & D_{3} & D_{4} \\ -D_{2} & D_{1} & -D_{4} & D_{3}\end{array}\right]^{T}$

where:

$D_{1}=(\mu-1)\left(\frac{1}{\kappa \tau_{s}}+\frac{1}{\kappa \tau_{r}}\right)$

$D_{2}=-(\mu-1) \omega_{r e}$

$D_{3}=\left(\mu^{2}-1\right)\left[\left(\frac{1}{\kappa \tau_{s}}+\frac{1}{\kappa \tau_{r}}\right) \frac{\kappa L_{s} M}{L_{r}}-\frac{M}{\tau_{r}}\right]$ $+\frac{\kappa L_{s} M}{L_{r}}\left(\frac{1}{\kappa \tau_{s}}+\frac{1}{\kappa \tau_{r}}\right)(\mu-1)$

$D_{4}=-(\mu-1) \frac{\kappa L_{s} M}{L_{r}} \omega_{r}$

with $\mu$ as a positive gain.

\subsection{Fault detection, isolation and reconfiguration}

In the proposed fault-tolerant control method against current sensors failure, measuring of the line currents $I_{a}, I_{b}$, and $I_{c}$ is performed by three Hall effect current sensors (sensor- $a$, sensor- $b$, and sensor- $c$ ) placed in the corresponding phases $a, b$, and $c$. However, the estimation is carried out by the proposed stator currents estimator previously presented in Fig. 4.

The logic circuit presented in Fig. 5(a) is intended to ensure the Fault Detection (FD), by analyzing the residual signal between measured and estimated quantities. A Low Pass Filter (LPF) is used in order to extract the useful signal, which will be compared to a threshold $(T h=0.45)$ that is empirically determined by assuming a threshold of $20 \%$ of IM rated stator current. The different test scenarios presented in Appendix B (low, rated and high speed, and load variation), show that the maximum error between the estimated currents and the measured currents is lower than $0.40 \mathrm{~A}$, for this reason, a threshold of $0.45 \mathrm{~A}$ has been chosen for this application, which correspond to $17 \%$ of the rated current of the IM.

At every sampling instant, the FD logic circuit generates three impulses $\mathrm{Ea}, \mathrm{Eb}$, and Ec as follows:

$E n=\left\{\begin{array}{l}0 \quad \text { if } I_{n} \text { is in Healthy state } \\ 1 \quad \text { if } I_{n} \text { is in Faulty state }\end{array} \quad\right.$ with: $n=a, b, c$

These three impulses $(E a, E b$, and $E c)$ are passed into an algorithm that allows generating an index $\mathrm{Z}$ (Fig. 6). Depending on the sensor states, this index can takes integer values from 0 to 7 . The different possible combinations of sensor states are summarized in Table I. According to $\mathrm{Z}$ values in Fig. 6, a multi-port switch is used to select the proper current components to replace the missing sensor's information (see Fig. 5(b)). It is clear that in the case of only one faulty current sensor, the missing current data will be replaced by the measurements from the two other healthy sensors by applying Kirchhoff's currents law to the neutral node, as follows:

$I_{a \text { mes }}+I_{b \text { mes }}+I_{c \text { mes }}=I_{N}=0$

Table 1. Phase sensors fault determination with proper selection of corrected value of $\mathrm{a}, \mathrm{b}$, and c currents

\begin{tabular}{|l|c|c|c|c|}
\hline $\begin{array}{l}\text { Phase- } \\
\text { a } \\
\text { sensor }\end{array}$ & $\begin{array}{c}\text { Phase-b } \\
\text { sensor }\end{array}$ & $\begin{array}{c}\text { Phase-c } \\
\text { sensor }\end{array}$ & $\mathbf{Z}$ & Proper selected currents \\
\hline Faulty & Healthy & Healthy & $\mathbf{1}$ & $-\left(I_{b \text { mes }}+I_{c \text { mes }}\right), I_{b \text { mes }}$ and $I_{c \text { mes }}$ \\
\hline Healthy & Faulty & Healthy & $\mathbf{2}$ & $I_{a \text { mes }},-\left(I_{a \text { mes }}+I_{c \text { mes }}\right)$ and $I_{c \text { mes }}$ \\
\hline Healthy & Healthy & Faulty & $\mathbf{3}$ & $I_{a \text { mes }}, I_{b \text { mes }}$ and $-\left(I_{a \text { mes }}+I_{b \text { mes }}\right)$ \\
\hline Faulty & Faulty & Healthy & $\mathbf{4}$ & $I_{a \text { est }}, I_{b e s t}$ and $I_{c \text { mes }}$ \\
\hline Faulty & Healthy & Faulty & $\mathbf{5}$ & $I_{a e s t}, I_{b \text { mes }}$ and $I_{c e s t}$ \\
\hline Healthy & Faulty & Faulty & $\mathbf{6}$ & $I_{a \text { mes }}, I_{b e s t}$ and $I_{c e s t}$ \\
\hline Faulty & Faulty & Faulty & $\mathbf{7}$ & $I_{a \text { est }}, I_{b e s t}$ and $I_{c \text { est }}$ \\
\hline Healthy & Healthy & Healthy & $\mathbf{0}$ & $I_{a \text { mes }}, I_{b m e s}$ and $I_{c \text { mes }}$ \\
\hline
\end{tabular}

The scheme of the proposed fault-tolerant control against current sensors failure is presented in Fig. 7. The suggested technique uses only one observer in order to reconstruct the three line currents $(a, b$, and $c)$. This estimator is fed by the electrical angular speed and the three-phase stator voltages. A voltage vector synthesizer constructs the three-phase stator voltages from the dc-link voltage sensor, using the switching signals $S a, S b$, and $S c$ obtained via three hysteresis controllers.

\section{Simulation results}

The behavior of the proposed fault-tolerant control is verified under MATLAB/Simulink environment, using the motor parameters presented in Table A.1 of Appendix A. Simulation results are presented in the next sub-sections, where a variety of tests are performed, such as low speed and variable speed with rated load, and high speed with variable load torque.

\subsection{Successive sensor gain faults in sensor-b and sensor- $c$ while sensor-a remains healthy}

To simplify the manipulation of the sensor gain fault in both simulation and experimental tests, a MATLAB/Simulink block has been introduced to change 
the gain of the current sensors. Fig. 8 displays the block diagram used to trigger the gain fault in the current sensors.

The simulation results presented in Fig. 9 show the effectiveness of the suggested FTC method against gain faults in two current sensors. The system was firstly started in a healthy state and at $t=2 \mathrm{~s}$, a gain fault was introduced in the current sensor- $b$. Soon after the fault occurrence, the $Z$ index generated by the FD algorithm takes the value of 2 (Fig. 9(e)), which indicates that sensor-b provides faulty measurements, as depicted in Fig. 9(b). Quickly, and using the multi-port switch, these erroneous measurements are replaced by proper current components $-\left(I_{a \text { mes }}+I_{c \text { mes }}\right)$. Successively, another gain fault was introduced in the sensor- $c$ at $t=4 \mathrm{~s}$. The $Z$ index changes rapidly to 6 (Fig. $9(\mathrm{e})$ ), which means that sensor- $b$ and sensor- $c$ provide improper measurements, as shown in Fig. 9(b) and (c). A quick decision is taken by the FDIR mechanism replacing the faulty sensors by a proper estimation corresponding to $Z=6$ (Table I). Consequently, the high-performance speed tracking, even under sensor faulty conditions, can be clearly observed from measured and reference speeds plotted in Fig. 9(d). Moreover, Fig. 9(f) shows the electromagnetic torque which is kept steady even under the sensors' fault occurrence. Fig. $9(\mathrm{~g})$ confirms also the decoupling between the direct and quadrature axes.

\subsection{Complete outage of the three current sensors in succession}

The simulation results obtained from applying the proposed FTC algorithm against the successive occurrence of total failures in sensors $c, a$, and $b$ are depicted in Fig. 10. The simulation scenario can be described as follows: firstly, the system is started in healthy operating conditions until $t=2 s$, when a fault in the sensor-c is suddenly introduced. The FD algorithm reacts quickly by generating an index $Z$ equal to 3, warning that sensor-c has totally failed. This gives an order to the multi-port switch to replace the missed information of sensor-c by proper calculation $-\left(I_{a \text { mes }}+I_{b \text { mes }}\right)$ from the other two healthy sensors (Table I), thus avoiding an interrupted operation of the system. In order to increase the fault severity, a second total fault is introduced in the sensor- $a$ at $t=4 \mathrm{~s}$. Successively, and just after one second, the third current sensor fails. Obviously, Fig. 10(e) shows clearly the reaction of the proposed FD algorithm by modifying the $\mathrm{Z}$ index value according to the actual operating situation. Indeed, at $t=$ $4 s$, the $Z$ value changes from 3 to 5 , thus warning that sensor- $a$ and sensor- $c$ are both under failure. Automatically, the multi-port switch chooses the input corresponding to $Z=5$ in order to replace the failed sensors with proper estimated currents $I_{a}$ est and $I_{c \text { est }}$. At $t=5 \mathrm{~s}$, the $Z$ index value rises to 7 (Fig. 10(e)) demonstrating a total failure in the three-phase current sensors. Even under this high fault severity, the proposed FDIR mechanism maintains the speed tracking performance by replacing the faulty current measurements with those estimated (Fig. 10(d)).

\subsection{Start-up with offset fault in the three current sensors}

This test was performed in order to evaluate the response of the proposed method versus a start-up with failures in the current sensors, as well as to test the reaction of this algorithm during the recovery of the sensors. At boot time, the fault indicator is $Z=7$, which confirms that the threephase current sensors are in the faulty state. Under these conditions, estimated currents are used from the beginning to ensure a successful start-up operating system. The actual and estimated stator currents are presented in Fig. 11(a), 11(b) and 11(c). As can be clearly seen, the offset in sensor$a$ is removed after $2 \mathrm{~s}$, recovering the healthy state of the sensor-a. As shown in Fig. 11(e), the proposed FD algorithm responds instantaneously and modifies the fault index to $Z=6$, confirming the recovery of sensor- $a$ on one side, and signaling, on the other side, that sensor- $b$ and sensor-c are still in faulty state. Subsequently, the offset in sensor- $b$ and in sensor- $c$ are successively removed at $t=3.5 \mathrm{~s}$ and $t=5 \mathrm{~s}$ (Fig. 11(b) and 11(c)). As expected, the proposed FD algorithm reacts to any events that occur during the system operation. Indeed, the fault index changes to 3 at $t=3.5 \mathrm{~s}$ and becomes 0 at $t=5 \mathrm{~s}$ (Fig. 11(e)), which describes perfectly the real changes introduced on the current sensors. According to Fig. 11(d), where speed tracking is plotted, it is confirmed that regardless of the faults in the current sensors, the proposed FTC scheme has the ability to guarantee an uninterrupted drive's operation with all required performance.

\subsection{Variable speed with sensor failures}

In order to evaluate and to prove the robustness of the proposed fault-tolerant control method and currents estimation, a test during variable speed with sensor failures and rated load is performed. Different failures are introduced in the current sensors (positive gain, negative gain, and complete outage of the sensor) such as depicted in Figs. 12(a), 12(b), and 12(c), where measured and estimated stator currents are plotted, knowing that at time moments $t=1 s, \quad t=2.5 s$ and $t=4 s$, sensor- $b$, sensor- $c$, and sensor-a becomes faulty in succession. Fig. 12(e) shows that the fault index values $(Z)$, describes correctly the current sensors state conditions. Moreover, Fig. 12(f) shows the electromagnetic torque under the sensors' fault occurrence and speed variation. Fig. 9(g) confirms also the decoupling between the direct and quadrature axes. Looking to Fig. 12(d), one can see the perfect tracking of the speed reference variation from 0 to $41 \%$ of the nominal speed, then growing up until $97 \%$, after that, going down to $7 \%$ and increasing to $28 \%$. It is clear that this hard scenario didn't affect the effectiveness of the proposed FDIR method and the target performances have been successfully obtained.

\subsection{Variable load with sensor failures}

For the same purpose as the previous test, the aim of this simulation is to examine the proposed FDIR method during sudden load torque variations with a constant speed of 136 $\mathrm{rad} / \mathrm{s}$. The current sensors fail successively as shown in Figs. 13(a), 13(b) and 13(c), sensor- $b$ at $=1 s$, sensor- $c$ at $t=2.5 \mathrm{~s}$ and sensor- $a$ at $t=4 \mathrm{~s}$. Fig. 13(d) shows highperformance speed tracking during all the tests even under faulty current sensors and variable load torque. At each moment of fault occurrence, the fault detection algorithm indicates the failure occurrence and the faulty sensor, such as explained previously in Table 1 and presented in Fig. 13(e) where the fault indicator is plotted. Fig. 13(f) presents the variation of the load torque $T_{L}^{*}$ and the electromagnetic torque $T_{e m}$, starting from $0 \mathrm{~N} . \mathrm{m}$ growing up to $3 \mathrm{~N} . \mathrm{m}$ then 
to $5 \mathrm{~N} . \mathrm{m}$, decreasing to $1.5 \mathrm{~N} . \mathrm{m}$. The decoupling between the direct and quadrature axes is conserved, which can be concluded from Fig. 13(g), where direct and quadrature stator currents are plotted. Like the previous test, this scenario didn't affect the suggested method.

\section{Experimental results}

The effectiveness of the proposed FTC scheme against current sensors failure for an IRFOC based IM drive is validated using the experimental test bench shown in Fig. 14. The experimental setup is composed of a $1.1 \mathrm{~kW} 4$-poles three-phase IM whose parameters are the same used in the simulation model (see Appendix A), a dSpace 1104 card, an autotransformer, an incremental encoder, a DC-voltage sensor, three Hall effect current sensors, a power electronics Semikron module (consisting of a rectifier and an IGBT inverter) and a powder brake. The proposed FTC scheme is implemented in real-time using the control desk software plugged in the computer.

\subsection{Successive sensor gain faults in sensor-b and sensor- c. Sensor-a remains healthy}

Fig. 15 presents the experimental results recorded under gain faults occurrence in sensor- $b$ and sensor- $c$. In this case, sensor- $a$ is kept healthy, but sensor- $b$ and sensor- $c$ are made faulty at $t=3.9 \mathrm{~s}$ and $t=7.1 \mathrm{~s}$, successively, by introducing a gain fault, as presented in Figs. 15(a), 15(b), and 15(c), respectively. Fig. 15(d) plots uninterrupted speed tracking performance under this adverse scenario. All these events are detected and identified by the proposed FD algorithm, as depicted in Fig. 15(e). Indeed, the fault index which was equal to 0 at the beginning of the system operation becomes 2 at $t=3.9 \mathrm{~s}$ and then, rises to 6 at $t=7.1 \mathrm{~s}$. The $\mathrm{Z}$ index values trigger the multi-port switch to replace the wrong measurements by the proper estimated currents. Fig. 15(f) displays uninterrupted fullfilment of load torque requirements under these conditions. Direct and quadrature stator currents are shown in Fig. 15(g), from which it can be seen that the concept of IRFOC is maintained.

\subsection{Complete outage of the three current sensors in succession}

For these experimental tests (Fig. 16), the IM drive system was started first, with healthy current sensors, which correspond to a fault index equal to 0 . From $3.95 \mathrm{~s}$, total failure is introduced in the sensor-c leading to a sudden interruption in the measurements of phase-c current. Instantaneously, the fault index becomes 3 , thus giving the order to replace the faulty sensor-c by a proper calculation. After that, the severity of this abnormal operating condition is increased by introducing total failures in sensor- $a$ and sensor- $b$ at $t=5.9 \mathrm{~s}$ and $t=7.95 \mathrm{~s}$, successively. Fig. 16(e) illustrates the changes that occurred in the fault index $(Z)$ which rises to 5 and then to 7 , identifying exactly the damaged current sensors and thus giving the order to replace the missing current measurements by the estimated ones (see Table I). Moreover, the result depicted in Fig. 16(d) confirms that the proposed FDIR mechanism has successfully maintained a high-performance speed tracking.

\subsection{Start-up with offset fault in the three current sensors}

This test has been conducted in order to verify the response and suitability of the suggested FTC scheme, and the proposed currents estimator in the case of a start-up transient with faulty current sensors, as well as to check the behavior of this strategy during sensors healthy state recovery. As can be seen from Figs. 17(a), 17(b), and 17(c), actual and estimated stator current components are recorded, when the start-up of the IM drive is performed with an offset failure in the three current sensors. At the power-up of the drive system, the fault index is equal to 7 (see Fig. 17(e)), confirming erroneous measurements provided by the three current sensors. In this adverse case, the multi-port switch selects the estimated currents to perform a successful startup (see Table I). As shown in Fig. 17(a), the offset in sensor- $a$ is removed at $t=4 \mathrm{~s}$, turning the sensor- $a$ to the healthy state. The fault index value changes to 6 , confirming the recovery of sensor- $a$ on one side, and depicting on the other side, that sensor- $b$ and sensor- $c$ are still in the faulty state. At $t=6 s$, the offset in sensor- $b$ is eliminated, such as depicted in Fig. 17(b). This makes sensor- $b$ in a healthy state. Soon after, the fault indicator $Z$ becomes 3 , which means that sensor- $a$ and sensor- $b$ are recovered, but sensor$c$ is kept in the faulty state. As can be seen from the resulting plot in Fig. 17(c), the offset in sensor-c is removed at $t=8.05 \mathrm{~s}$. Instantaneously, $\mathrm{Z}$ becomes 0 , judging the healthy state of the system. Actual and reference speeds are presented in Fig. 17(d) for a speed set of $21 \mathrm{rad} / \mathrm{s}$ at $5 \mathrm{Nm}$ load torque, which depicts a high-performance FTC operating system in such conditions.

\subsection{Variable speed with sensor failures}

Fig. 18 shows the experimental results of the proposed method for sensors fault detection and currents estimation under variable speed and rated load torque conditions. Sudden faults are introduced in the current sensors successively at $t=4.83 \mathrm{~s}, t=11.23 \mathrm{~s}$, and $t=19.2 \mathrm{~s}$. The measured and estimated currents are depicted in Figs. 18(a), 18(b) and 18(c). Fig. 18(d) shows the reference speed profile and the measured rotor speed in percent of the rated motor speed (see Table A.1 of Appendix A). The reference speed starts from $0 \%$ then growing up to $41 \%$, then to $96.5 \%$, after that, the reference speed decreases until $7 \%$ and increases to $27.5 \%$. As can be clearly seen, the speed variation scenario under current sensors failure didn't impact the functioning of the FDIR algorithm and currents estimator. At each moment of failure occurrence, the FDIR system reported the presence of a fault and the faulty sensor (Table 1), such as illustrated in Fig. 18(e), in which the fault indicator is displayed. Fig. 18(f) indicates the load torque and the variation of electromagnetic torques caused by speed variation. The direct and quadrature stator currents are depicted in Fig.18(g).

\subsection{Variable load with sensor failures}

Fig. 19 illustrates the experimental results recorded applying the fault-tolerant control system, in load variation condition. Figs. 19(a), 19(b), and 19(c) present the measured and estimated stator currents, knowing that the used three current sensors fail in succession. The Fig. 19(d) displays the speed reference step applied for this test as well as the measured rotor speed. The failures introduced in the three current sensors are normally detected and the faulty current sensors are identified, which is shown in Fig. 19(e), where 
the fault indicator signal is plotted, giving different values of $Z$ judging sensor failures such as presented previously in Table 1. The variation of the load and electromagnetic torques $\left(T_{L}^{*}\right.$ and $\left.T_{e m}\right)$ are presented in Fig. 19(f). In fact, they start from $0 \mathrm{~N} . \mathrm{m}$ to $2.8 \mathrm{~N} . \mathrm{m}$, then to $5 \mathrm{~N} . \mathrm{m}$ and finally decreases to $0.98 \mathrm{~N} . \mathrm{m}$. These results prove that the control performance stays achieved even with such hard scenario (faulty current sensors under load variations).

\section{Conclusion}

In this paper, a fault-tolerant control strategy for vector control of an IM drive against current sensor failures is proposed. The IRFOC strategy was used considering its simplicity, computation time, presence of a few PI controllers, and wide application to different AC electrical drives. A new modification of the Luenberger observer is proposed to ensure the estimation of the three stator currents from the dc-link voltage sensor and the speed encoder. A fault detection algorithm with a decision-making logic circuit has been applied for each phase, in order to identify the faulty sensor. Immediately after the failure of the current sensor(s), the FD algorithm generates an impulse fault index $\mathrm{Z}$ identifying the faulty sensor(s). Based on the $\mathrm{Z}$ values, the multi-port switch selects the correct current component(s), allowing the continuity of the drives and uninterrupted operation. The effectiveness, the response, and the highperformance of the suggested FTC strategy have been verified by a simulation model and validated in an experimental test bench. Both simulation and experimental tests present fast dynamic and good results of the proposed FDIR scheme and currents estimator, under current sensors failure in succession, even during the start-up transient, with variable speed and at variable load torque. Moreover, all the tests are performed at low speed with a sudden start-up under rated load using the diagnosis method in order to approve robustness against false alarms in healthy drive operation. As well as, the diagnosis accuracy has been validated and verified by analyzing three different faults (complete sensor outage, gain drop, and especially the startup with offset fault) under different conditions that can affect the measured quantities. In addition, the proposed currents estimation strategy is simple to use with other controllers such as direct torque control and sliding mode control. Furthermore, such as shown in simulation and experimentation, the proposed FDIR can be adaptively reorganized in the event of recovering the faulty sensors. This allows maintaining the maximum performance of the control system considering the complementary nature of the other sensors. In conclusion, it is obvious that the proposed FTC (FDIR and currents estimator) can be considered as an effective solution in crucial applications where current sensors are susceptible to failures. The high-accuracy of the stator currents estimation was a very important factor in the detection of sensor malfunctions. Therefore, the proposed FTC scheme has the ability to keep the system running with full performance, even under severe sensor failures occurrence. For industrial applications, the proposed method is easy to apply and inexpensive, due to its simplicity regarding the high-performance that she can ensure. As most of the cases, each method has its limits; the method proposed in this paper is not standard because its application is different from one system to another and sensitive to high temperatures given that causes a huge parametric variation.

\section{Appendix A}

Table A.1 Specifications and parameters of the induction motor used in simulation and experimental tests.

\begin{tabular}{|l|l|l|l|}
\hline \multicolumn{2}{|c|}{ Specifications } & \multicolumn{2}{c|}{ Parameters } \\
\hline Nominal power [kW] & 1.1 & $\mathrm{R}_{\mathrm{s}}[\Omega]$ & 6.75 \\
\hline Nominal voltage [V] & 400 & $\mathrm{R}_{\mathrm{r}}[\Omega]$ & 6.21 \\
\hline Nominal current [A] & 2.5 & $\mathrm{~L}_{\mathrm{s}}[\mathrm{H}]$ & 0.5192 \\
\hline Frequency [Hz] & 50 & $\mathrm{~L}_{\mathrm{r}}[\mathrm{H}]$ & 0.5192 \\
\hline Number of pole pairs & 2 & $\mathrm{M}[\mathrm{H}]$ & 0.4957 \\
\hline Nominal speed [rpm] & 1450 & $\mathrm{~J}\left[\mathrm{Kg} \cdot \mathrm{m}^{2}\right]$ & 0.0124 \\
\hline & & $\mathrm{f}\left[\mathrm{Nm} . \mathrm{s}_{\mathrm{rad}}{ }^{-1}\right]$ & 0.002 \\
\hline
\end{tabular}

Table A.2 PI regulator values used in simulation and experimental tests.

\begin{tabular}{|c|c|c|c|}
\hline \multicolumn{2}{|c|}{ Simulation } & Experimental implementation \\
\hline$K p_{\omega}=0.329$ & $K i_{\omega}=2.8$ & $K p_{\omega}=0.02$ & $K i_{\omega}=0.674$ \\
\hline \multicolumn{2}{|c|}{$\mu=1.004$} \\
\hline \multicolumn{2}{|c|}{$\mu=1.001$} & \multicolumn{2}{|c|}{$\mu=1$} \\
\hline
\end{tabular}

\section{Appendix B}

\begin{tabular}{|c|c|c|c|c|}
\hline \multicolumn{5}{|c|}{ Threshold determination } \\
\hline & \multicolumn{4}{|c|}{$T_{L}=0 \mathrm{~N} . \mathrm{m} ; \omega_{r}=105 \mathrm{rad} / \mathrm{s}$} \\
\hline MAX & $|\Delta I|$ at TR & $|\Delta I|$ at $\mathbf{C R}$ & $|\Delta I|$ & \\
\hline$\left|\Delta I_{a}\right|$ & 0,315 & 0,265 & $\left|\Delta \boldsymbol{I}_{\boldsymbol{a}}\right|<0,35$ & \multirow{3}{*}{$T h=0.45$} \\
\hline$\left|\Delta I_{b}\right|$ & 0,319 & 0,271 & $\left|\Delta \boldsymbol{I}_{b}\right|<0,35$ & \\
\hline$\left|\Delta \boldsymbol{I}_{c}\right|$ & 0,323 & 0,269 & $\left|\Delta \boldsymbol{I}_{c}\right|<0,35$ & \\
\hline & \multicolumn{4}{|c|}{$T_{L}=2 \mathrm{~N} . \mathrm{m} ; \omega_{r}=105 \mathrm{rad} / \mathrm{s}$} \\
\hline MAX & $|\Delta I|$ at TR & $|\Delta I|$ at $\mathbf{C R}$ & $|\Delta I|$ & \\
\hline$\left|\Delta I_{a}\right|$ & 0,306 & 0,249 & $\left|\Delta \boldsymbol{I}_{a}\right|<0,35$ & \multirow{3}{*}{$T h=0.45$} \\
\hline$\left|\Delta I_{b}\right|$ & 0,348 & 0,257 & $\left|\Delta I_{b}\right|<0,35$ & \\
\hline$\left|\Delta I_{c}\right|$ & 0,361 & 0,284 & $\left|\Delta I_{c}\right|<0,40$ & \\
\hline & \multicolumn{4}{|c|}{$T_{L}=5 \mathrm{~N} . \mathrm{m} ; \omega_{r}=105 \mathrm{rad} / \mathrm{s}$} \\
\hline MAX & $|\Delta I|$ en TR & $|\Delta I|$ at $\mathbf{C R}$ & $|\Delta I|$ & \\
\hline$\left|\Delta I_{a}\right|$ & 0,326 & 0,214 & $\left|\Delta \boldsymbol{I}_{a}\right|<0,35$ & \multirow{3}{*}{$T h=0.45$} \\
\hline$\left|\Delta I_{b}\right|$ & 0,312 & 0,234 & $\left|\Delta \boldsymbol{I}_{\boldsymbol{b}}\right|<0,35$ & \\
\hline$\left|\Delta \boldsymbol{I}_{c}\right|$ & 0,334 & 0,229 & $\left|\Delta \boldsymbol{I}_{c}\right|<0,35$ & \\
\hline & \multicolumn{4}{|c|}{$T_{L}=0 \mathrm{~N} . \mathrm{m} ; \omega_{r}=21 \mathrm{rad} / \mathrm{s}$} \\
\hline MAX & $|\Delta I|$ en TR & $|\Delta I|$ at $\mathbf{C R}$ & $|\Delta I|$ & \\
\hline$\left|\Delta I_{a}\right|$ & 0.348 & 0,265 & $\left|\Delta \boldsymbol{I}_{\boldsymbol{a}}\right|<0,35$ & \multirow{3}{*}{$T h=0.45$} \\
\hline$\left|\Delta I_{b}\right|$ & 0.315 & 0,2612 & $\left|\Delta \boldsymbol{I}_{\boldsymbol{b}}\right|<0,35$ & \\
\hline$\left|\Delta I_{c}\right|$ & 0.387 & 0,239 & $\left|\Delta \boldsymbol{I}_{c}\right|<0,40$ & \\
\hline & \multicolumn{4}{|c|}{$T_{L}=2 \mathrm{~N} . \mathrm{m} ; \omega_{r}=21 \mathrm{rad} / \mathrm{s}$} \\
\hline MAX & $|\Delta I|$ en TR & $|\Delta I|$ at $\mathbf{C R}$ & $|\Delta I|$ & \\
\hline$\left|\Delta I_{a}\right|$ & 0.379 & 0,281 & $\left|\Delta I_{a}\right|<0,40$ & \multirow{3}{*}{$T h=0.45$} \\
\hline$\left|\Delta I_{b}\right|$ & 0.366 & 0,272 & $\left|\Delta I_{b}\right|<0,40$ & \\
\hline$\left|\Delta I_{c}\right|$ & 0.328 & 0,233 & $\left|\Delta \boldsymbol{I}_{c}\right|<0,35$ & \\
\hline & \multicolumn{4}{|c|}{$T_{L}=5 \mathrm{~N} . \mathrm{m} ; \omega_{r}=21 \mathrm{rad} / \mathrm{s}$} \\
\hline MAX & $|\Delta I|$ en TR & $|\Delta I|$ at $\mathbf{C R}$ & $|\Delta I|$ & \\
\hline$\left|\Delta I_{a}\right|$ & 0.364 & 0,251 & $\left|\Delta I_{a}\right|<0,40$ & \multirow{3}{*}{$T h=0.45$} \\
\hline$\left|\Delta I_{b}\right|$ & 0.337 & 0,278 & $\left|\Delta \boldsymbol{I}_{\boldsymbol{b}}\right|<0,35$ & \\
\hline$\left|\Delta I_{c}\right|$ & 0.346 & 0,250 & $\left|\Delta \boldsymbol{I}_{c}\right|<0,35$ & \\
\hline
\end{tabular}

TR: Transient Regime

CR: Continuous Regime 


\section{Appendix C}

Comparison between the suggested method and relevant methods over the last ten years.

\begin{tabular}{|l|c|c|c|c|c|c|c|}
\hline & {$[26]$} & {$[28]$} & {$[27]$} & {$[51]$} & {$[30,31]$} & {$[37,38,40]$} & Suggested method \\
\hline $\begin{array}{l}\text { Failure succession in } \\
\text { the different sensors }\end{array}$ & $\begin{array}{c}\text { Unsuitable } \\
\text { to detect }\end{array}$ & $\begin{array}{c}\text { Unsuitable } \\
\text { to detect }\end{array}$ & $\begin{array}{c}\text { Suitable } \\
\text { to detect }\end{array}$ & $\begin{array}{c}\text { Suitable } \\
\text { to detect }\end{array}$ & $\begin{array}{c}\text { Suitable } \\
\text { to detect }\end{array}$ & $\begin{array}{c}\text { Suitable to } \\
\text { detect }\end{array}$ & Suitable to detect \\
\hline $\begin{array}{l}\text { Number of current } \\
\text { estimators }\end{array}$ & $\mathbf{3}$ & $\mathbf{3}$ & $\mathbf{3}$ & $\mathbf{0}$ & $\mathbf{0}$ & $\mathbf{1}$ & $\mathbf{1}$ \\
\hline $\begin{array}{l}\text { Number of used } \\
\text { current sensors }\end{array}$ & $\mathbf{2}$ & $\mathbf{1}$ & $\mathbf{1}$ & $\mathbf{0}$ & $\mathbf{0}$ & $\mathbf{0}$ & $\mathbf{0}$ \\
\hline Number of controllers & $\mathbf{1}$ & $\mathbf{1}$ & $\mathbf{1}$ & $\mathbf{4}$ & $\mathbf{3}$ & $\mathbf{1}$ & $\mathbf{1}$ \\
\hline $\begin{array}{l}\text { Considered sensor } \\
\text { faults }\end{array}$ & $\begin{array}{c}\text { Complete } \\
\text { outage }\end{array}$ & $\begin{array}{c}\text { Complete } \\
\text { outage and } \\
\text { gain fault }\end{array}$ & $\begin{array}{c}\text { Complet } \\
\text { e outage } \\
\text { and gain } \\
\text { fault }\end{array}$ & $\begin{array}{c}\text { Complet } \\
\text { e outage } \\
\text { and gain } \\
\text { fault }\end{array}$ & $\begin{array}{c}\text { Complet } \\
\text { e outage } \\
\text { and gain } \\
\text { fault }\end{array}$ & $\begin{array}{c}\text { Complete } \\
\text { outage and } \\
\text { gain fault }\end{array}$ & $\begin{array}{c}\text { Complete outage, } \\
\text { gain fault, and } \\
\text { offset }\end{array}$ \\
\hline $\begin{array}{l}\text { Sensitive to parametric } \\
\text { variation }\end{array}$ & Sensitive & Sensitive & Sensitive & Sensitive & Sensitive & Sensitive & $\begin{array}{c}\text { Insensitive except } \\
\text { in high } \\
\text { temperature } \\
\text { operation }\end{array}$ \\
\hline
\end{tabular}

\section{Nomenclature}

$\begin{array}{ll}V_{d c} & \text { DC-link voltage } \\ V_{s} & \text { Three phases stator voltages } \\ I_{a}, I_{b}, I_{c} & (a, b, c) \text { axis stator currents } \\ V_{s d}, V_{s q} & (d, q) \text { axis stator voltages } \\ I_{s d}, I_{s q} & (d, q) \text { axis stator currents } \\ \varphi_{r d}, \varphi_{r q} & (d, q) \text { axis rotor fluxes } \\ \tau_{s}, \tau_{r} & \text { Stator and rotor time constantes } \\ V_{s \alpha}, V_{s \beta} & (\alpha, \beta) \text { axis stator voltages } \\ I_{s \alpha}, I_{s \beta} & (\alpha, \beta) \text { axis stator currents } \\ \widehat{I_{s \alpha}}, \widehat{I_{s \beta}} & (\alpha, \beta) \text { axis estimated stator currents } \\ \varphi_{r \alpha}, \varphi_{r \beta} & (\alpha, \beta) \text { axis rotor fluxes } \\ \widehat{\varphi_{r \alpha}}, \widehat{\varphi_{r \beta}} & (\alpha, \beta) \text { axis estimated rotor fluxes } \\ \varphi_{r} & \text { Rotor flux magnitude } \\ \omega_{s} & \text { Synchronous speed } \\ \omega_{r} & \text { Rotor angular speed } \\ \omega_{e} & \text { Electrical angular speed } \\ \Omega_{r} & \text { Mechanical speed } \\ T_{e}, T_{l} & \text { Electromagnetic and load torques }\end{array}$

\section{References}

[1] F. Blaschke. The Principle of Field Orientation as Applied to the New Transvector Closed-Loop System for Rotating-Field Machines. Siemens Rev 1972;34:217-20.

[2] Mendes AMS, Marques Cardoso AJ. Fault-Tolerant Operating Strategies Applied to Three-Phase Induction-Motor Drives. IEEE Trans Ind Electron 2006;53:1807-17. doi:10.1109/TIE.2006.885137.

[3] Bin Lu, Sharma SK. A Literature Review of IGBT Fault Diagnostic and Protection Methods for Power Inverters. IEEE Trans Ind Appl 2009;45:1770-7. doi:10.1109/TIA.2009.2027535.

[4] Errabelli RR, Mutschler P. Fault-Tolerant Voltage Source Inverter for Permanent Magnet Drives. IEEE Trans Power Electron 2012;27:500-8. doi:10.1109/TPEL.2011.2135866

[5] Tabbache B, Benbouzid M, Kheloui A, Bourgeot J-M, Mamoune A. An improved fault-tolerant control scheme for PWM inverter-fed induction motor-based EVs. ISA Trans 2013;52:862-9. doi:10.1016/j.isatra.2013.07.004.
[6] Berriri H, Naouar MW, Slama-Belkhodja I. Easy and Fast Sensor Fault Detection and Isolation Algorithm for Electrical Drives. IEEE Trans Power Electron 2012:27:490_9. doi:10.1109/TPEL.2011.2140333.

[7] Yu Y, Chen X, Dong Z. Current sensorless direct predictive control for induction motor drives. 2017 IEEE Transp. Electrif. Conf. Expo, Asia-Pacific (ITEC Asia-Pacific), IEEE; 2017, p. 1-6. doi:10.1109/ITEC-AP.2017.8080975.

[8] Campos-Delgado DU, Espinoza-Trejo DR, Palacios E. Fault-tolerant control in variable speed drives: a survey. IET Electr Power App 2008:2:121-34. doi:10.1049/iet-epa:20070203.

[9] Balaban E, Saxena A, Bansal P, Goebel KF, Curran S. Modeling, Detection, and Disambiguation of Sensor Faults for Aerospace Applications. IEEE Sens J 2009;9:1907-17. doi:10.1109/JSEN.2009.2030284.

[10] Karimi S, Gaillard A, Poure P, Saadate S. Current Sensor FaultTolerant Control for WECS With DFIG. IEEE Trans Ind Electron 2009;56:4660-70. doi:10.1109/TIE.2009.2031193.

[11] Karimi S, Gaillard A, Poure P, Saadate S. FPGA-Based Real-Time Power Converter Failure Diagnosis for Wind Energy Conversion Systems. IEEE Trans Ind Electron 2008;55:4299-308. doi:10.1109/TIE.2008.2005244.

[12] Cronin MJJ. The all-electric aircraft. IEE Rev 1990;36:309. doi:10.1049/ir:19900132.

[13] de Lillo L, Empringham L, Wheeler PW, Khwan-On S, Gerada C Othman MN, et al. Multiphase Power Converter Drive for FaultTolerant Machine Development in Aerospace Applications. IEEE Trans Ind Electron 2010·57:575-83 doi:10.1109/TIE 2009.2036026.

[14] Diallo D, Benbouzid MEH, Makouf A. A Fault-Tolerant Control Architecture for Induction Motor Drives in Automotive Applications. IEEE Trans Veh Technol 2004;53:1847-55. doi:10.1109/TVT.2004.833610.

[15] Benbouzid MEH, Diallo D, Zeraoulia M. Advanced Fault-Tolerant Control of Induction-Motor Drives for EV/HEV Traction Applications: From Conventional to Modern and Intelligent Control Techniques. IEEE Trans Veh Technol 2007;56:519-28. doi:10.1109/TVT.2006.889579.

[16] Blanke M, Kinnaert M, Lunze J, Staroswiecki M. Diagnosis and Fault-Tolerant Control. 1st ed. Berlin, Heidelberg: Springer Berlin Heidelberg; 2003. doi:10.1007/978-3-662-05344-7.

[17] Blanke M, Kinnaert M, Lunze J, Staroswiecki M. Diagnosis and Fault-Tolerant Control. 2nd ed. Springer Berlin Heidelberg; 2006. doi:10.1007/978-3-540-35653-0.

[18] Alwi H, Edwards C, Pin Tan C. Fault Detection and Fault-Tolerant Control Using Sliding Modes. London: Springer London; 2011. doi:10.1007/978-0-85729-650-4.

[19] Hamayun MT, Edwards C, Alwi H. Fault Tolerant Control Schemes Using Integral Sliding Modes. vol. 61. Cham: Springer International Publishing; 2016. doi:10.1007/978-3-319-32238-4.

[20] Guezmil A, Berriri H, Pusca R, Sakly A, Romary R, Mimouni MF Experimental Investigation of Passive Fault Tolerant Control for Induction Machine Using Sliding Mode Approach. Asian J Control 2019;21:520-32. doi:10.1002/asjc.1753.

[21] Guezmil A, Berriri H, Pusca R, Sakly A, Romary R, Mimouni MF 
High order sliding mode observer-based backstepping fault-tolerant control for induction motor. Asian J Control 2019;21:33-42. doi:10.1002/asjc.2016.

[22] Bianchi N, Bolognani S, Zigliotto M, Zordan M. Innovative remedial strategies for inverter faults in IPM synchronous motor drives. IEEE Trans Energy Convers 2003;18:306-14. doi:10.1109/TEC.2002.808334

[23] Jasim O, Sumner M, Gerada C, Arellano-Padilla J. Development of a new fault-tolerant induction motor control strategy using an enhanced equivalent circuit model. IET Electr Power Appl 2011;5:618. doi:10.1049/iet-epa.2010.0235

[24] Foster M, Hoang KD, Zhu Z-Q. Direct torque control of permanent magnet brushless AC drive with single-phase open-circuit fault accounting for influence of inverter voltage drop. IET Electr Power Appl 2013;7:369-80. doi:10.1049/iet-epa.2012.0290.

[25] Gajanayake C, Bhangu BS, Foo G, Zhang X, Tseng KJ, Don Vilathgamuwa M. Sensor fault detection, isolation and system reconfiguration based on extended Kalman filter for induction motor drives. IET Electr Power Appl 2013;7:607-17. doi:10.1049/ietepa.2012.0308

[26] Yu Y, Wang Z, Xu D, Zhou T, Xu R. Speed and Current Sensor Fault Detection and Isolation Based on Adaptive Observers for IM

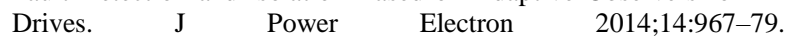
doi:10.6113/JPE.2014.14.5.967.

[27] Yu Y, Zhao Y, Wang B, Huang X, Xu D. Current Sensor Fault Diagnosis and Tolerant Control for VSI-Based Induction Motor Drives. IEEE Trans Power Electron 2018;33:4238-48. doi:10.1109/TPEL.2017.2713482.

[28] Grouz F, Sbita L, Boussak M. Current sensors faults detection, isolation and control reconfiguration for PMSM drives. 2013 Int. Conf. Electr. Eng. Softw. Appl., IEEE; 2013, p. 1-6. doi:10.1109/ICEESA.2013.6578414.

[29] Sepe RB, Fahimi B, Morrison C, Miller JM. Fault tolerant operation of induction motor drives with automatic controller reconfiguration. IEMDC 2001. IEEE Int. Electr. Mach. Drives Conf. (Cat. No.01EX485), IEEE; n.d., p. 156-62. doi:10.1109/IEMDC.2001.939291.

[30] Stettenbenz M, Liu Y, Bazzi A. Smooth switching controllers for reliable induction motor drive operation after sensor failures. 2015 IEEE Appl. Power Electron. Conf. Expo., IEEE; 2015, p. 2407-11. doi:10.1109/APEC.2015.7104685.

[31] Liu Y, Stettenbenz M, Bazzi AM. Smooth Fault-Tolerant Control of Induction Motor Drives with Sensor Failures. IEEE Trans Power Electron 2018;PP:1-1. doi:10.1109/TPEL.2018.2848964.

[32] Aguilera F, de la Barrera PM, De Angelo CH. A fault tolerant system for current sensors in induction motor drives. 2015 XVI Work. Inf. Process. Control, IEEE; 2015, p. 1-7. doi:10.1109/RPIC.2015.7497178.

[33] Tabbache B, Benbouzid M, Kheloui A, Bourgeot J-M. DSP-Based Sensor Fault Detection and Post Fault-Tolerant Control of an Induction Motor-Based Electric Vehicle. Int $\mathrm{J}$ Veh Technol 2012;2012:1-7. doi:10.1155/2012/608381.

[34] Tabbache B, Rizoug N, Benbouzid MEH, Kheloui A. A Control Reconfiguration Strategy for Post-Sensor FTC in Induction MotorBased EVs. IEEE Trans Veh Technol 2013;62:965-71. doi:10.1109/TVT.2012.2232325.

[35] Dybkowski M, Klimkowski K. Stator current sensor fault detection and isolation for vector controlled induction motor drive. 2016 IEEE Int. Power Electron. Motion Control Conf., IEEE; 2016, p. 1097102. doi:10.1109/EPEPEMC.2016.7752147.

[36] Klimkowski K, Dybkowski M. Neural network approach for stator current sensor fault detection and isolation for vector controlled induction motor drive. 2016 IEEE Int. Power Electron. Motion Control Conf., IEEE; 2016, p. 1072-8. doi:10.1109/EPEPEMC.2016.7752143.

[37] Manohar M, Das S. Current Sensor Fault-Tolerant Control for Direct Torque Control of Induction Motor Drive Using Flux-Linkage Observer. IEEE Trans Ind Informatics 2017;13:2824-33. doi:10.1109/TII.2017.2714675.

[38] Manohar M, Das S. Current Sensor Fault-Tolerant Control of Induction Motor Driven Electric Vehicle Using Flux-Linkage Observer. 2020 IEEE Transp. Electrif. Conf. Expo, IEEE; 2020, p. 884-9. doi:10.1109/ITEC48692.2020.9161553.

[39] Kang Y-C, Ok SH, Kang SH. A CT Saturation Detection Algorithm. IEEE Trans Power Deliv 2004;19:78-85. doi:10.1109/TPWRD.2003.820200.

[40] Manohar M, Das S, Kumar R. A robust current sensor fault detection scheme for sensorless induction motor drive. 2017 IEEE PES AsiaPacific Power Energy Eng. Conf., IEEE; 2017, p. 1-6. doi:10.1109/APPEEC.2017.8308967.

[41] Bala M, Bahri I, Mercier A, Khanchoul M, Krebs G. A Speed PMSM Control Technique With a Single DC Bus current Sensor. IECON 2019 - 45th Annu. Conf. IEEE Ind. Electron. Soc., vol. 1, IEEE; 2019, p. 243-8. doi:10.1109/IECON.2019.8927460.

[42] Bala M, Bahri I, Mercier A, Khanchoul M, Krebs G. Speed PMSM Control Technique using a Single Current Sensor with Random SVPWM. 2020 IEEE 29th Int. Symp. Ind. Electron., IEEE; 2020, p. 1547-52. doi:10.1109/ISIE45063.2020.9152452.

[43] Li S, Bai B, Chen D. Vector Control of Permanent Magnet Synchronous Motor by Using Single Current Sensor. ICPE 2019 ECCE Asia - 10th Int. Conf. Power Electron. - ECCE Asia, 2019, p. 2556-61.

[44] Metidji B, Taib N, Baghli L, Rekioua T, Bacha S. Low-Cost Direct Torque Control Algorithm for Induction Motor Without AC Phase Current Sensors. IEEE Trans Power Electron 2012;27:4132-9. doi:10.1109/TPEL.2012.2190101.

[45] Noordeen S, Karthikeyan K, Parveen M a N. Direct Torque Control for Induction Motor Without Current Sensors. Int J Eng Res Technol 2013;2:388-97.

[46] Aminoroaya I, Vaez-Zadeh S. Permanent magnet synchronous motor control using DC-Link current regulation. IECON 2016 - 42nd Annu. Conf. IEEE Ind. Electron. Soc., IEEE; 2016, p. 7077-82. doi:10.1109/IECON.2016.7793899.

[47] Wang W, Yan H, Xu Y, Zou J, Zhang X, Zhao W, et al. New ThreePhase Current Reconstruction for PMSM Drive with Hybrid Space Vector Pulse Width Modulation Technique. IEEE Trans Power Electron 2020;8993:1-1. doi:10.1109/TPEL.2020.2997986.

[48] Yongchang Zhang, Zhengming Zhao, Ting Lu, Liqiang Yuan, Wei $\mathrm{Xu}$, Jianguo Zhu. A comparative study of Luenberger observer, sliding mode observer and extended Kalman filter for sensorless vector control of induction motor drives. 2009 IEEE Energy Convers. Congr. Expo., IEEE; 2009, p. 2466-73. doi:10.1109/ECCE.2009.5316508.

[49] Luenberger D. An introduction to observers. IEEE Trans Automat Contr 1971;16:596-602. doi:10.1109/TAC.1971.1099826.

[50] Kautsky J, Nichols NK, Van Dooren P. Robust pole assignment in linear state feedback. Int J Control 1985;41:1129-55. doi:10.1080/0020718508961188.

[51] Sepe RB, Fahimi B, Morrison C, Miller JM. Fault tolerant operation of induction motor drives with automatic controller reconfiguration. IEMDC 2001. IEEE Int. Electr. Mach. Drives Conf. (Cat. No.01EX485), vol. 3, IEEE; 2003, p. 156-62. doi:10.1109/IEMDC.2001.939291

\section{Figures}

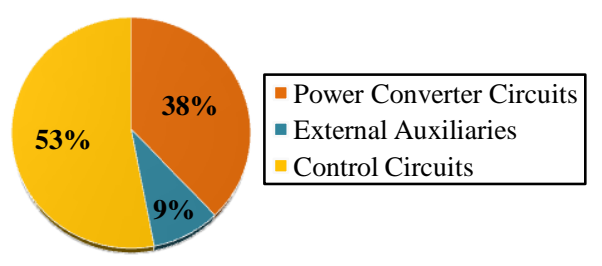

Fig. 1 Failure distribution in adjustable speed drives. 


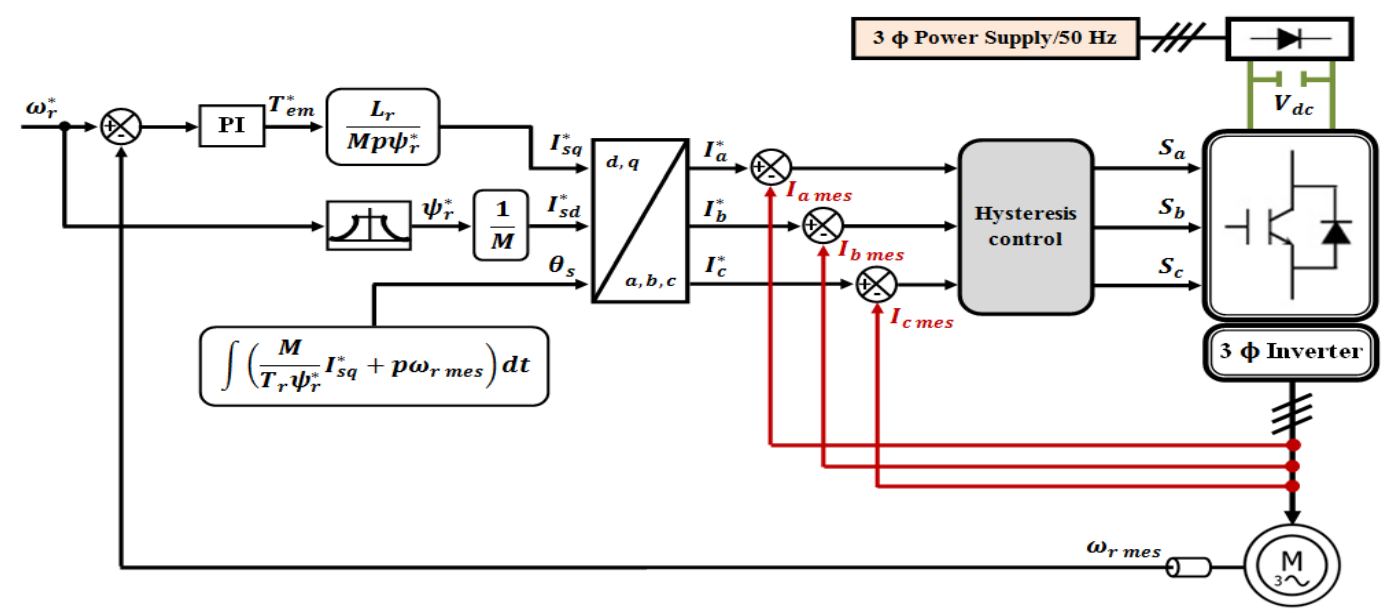

Fig. 2 Basic indirect rotor field oriented control scheme.

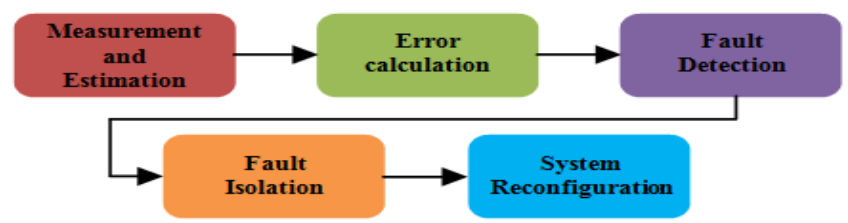

Fig. 3 Main steps to achieve the proposed fault-tolerant control method.


Fig. 5 Current sensors fault detection, isolation and reconfiguration mechanism: (a) Fault detection logic circuit, (b) multi-port switch for proper reconfiguration of $\mathrm{a}, \mathrm{b}$, and $\mathrm{c}$ current components.

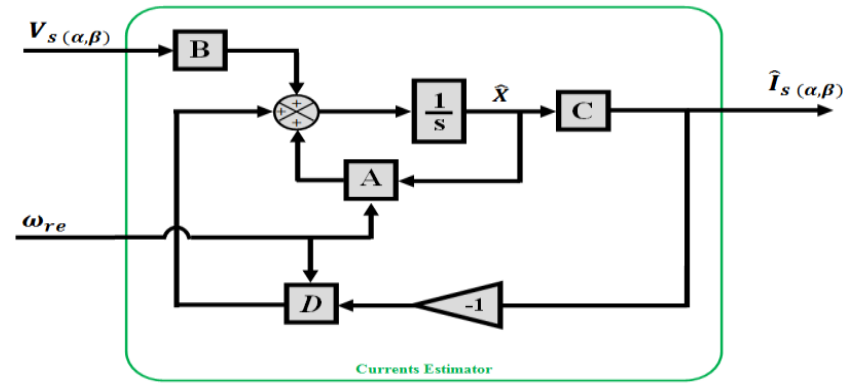

Fig. 4 Proposed stator currents estimator.

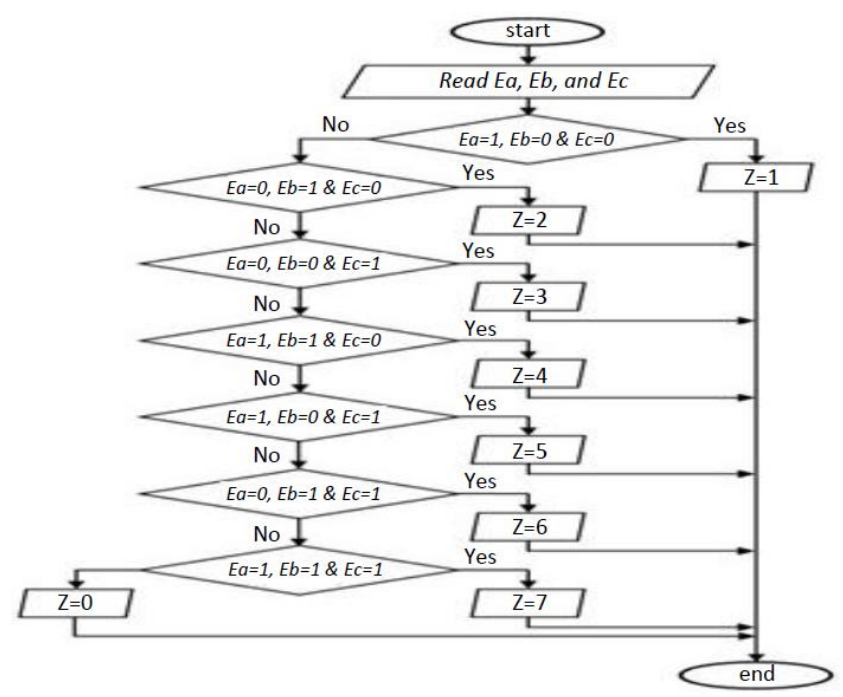

Fig. 6 Flow-chart of faulty sensors determination algorithm 


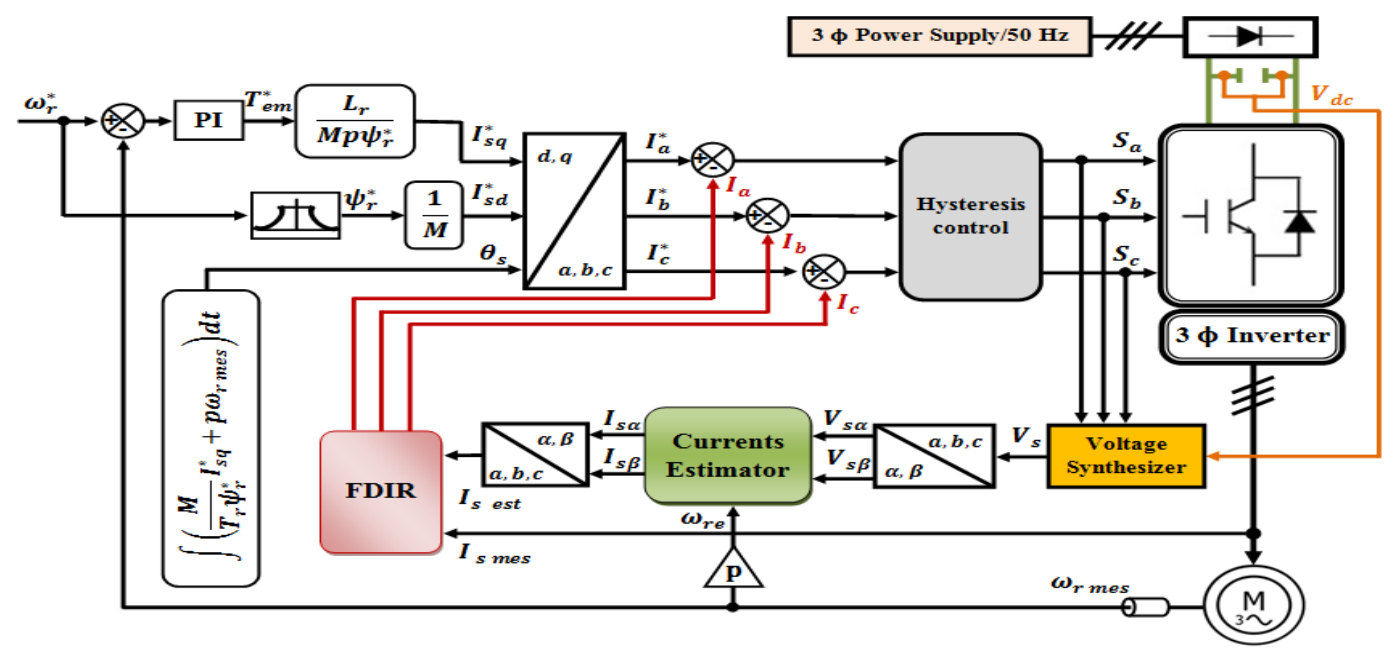

Fig. 7 Scheme of the proposed fault-tolerant control against current sensors failure.

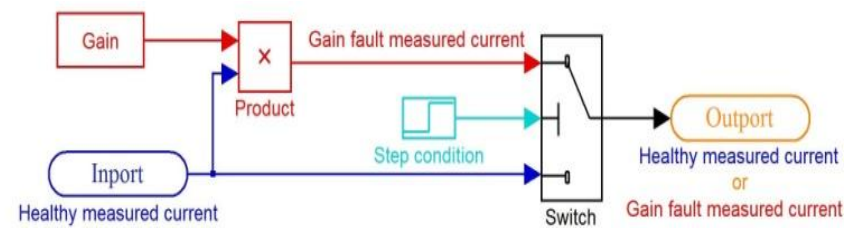

Fig. 8 Block diagram of gain fault creation in the current sensors.
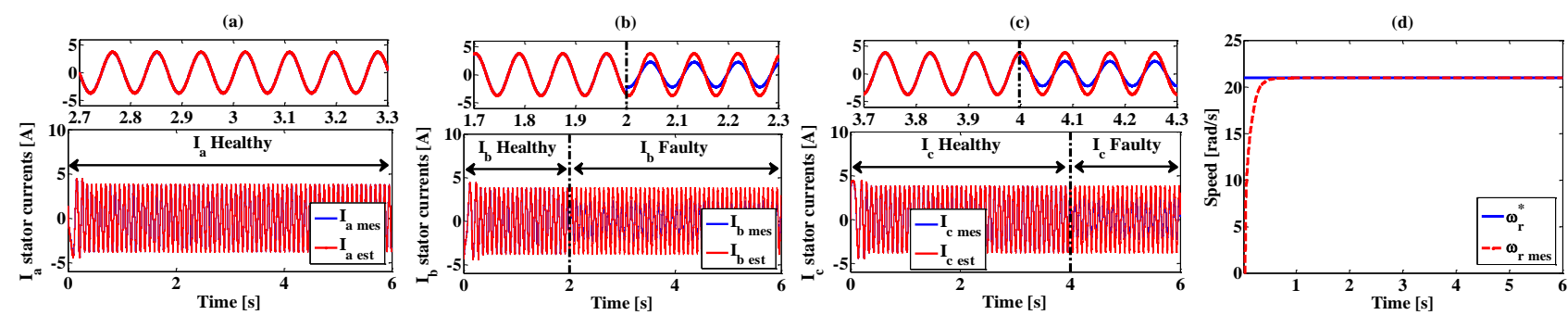

(e)
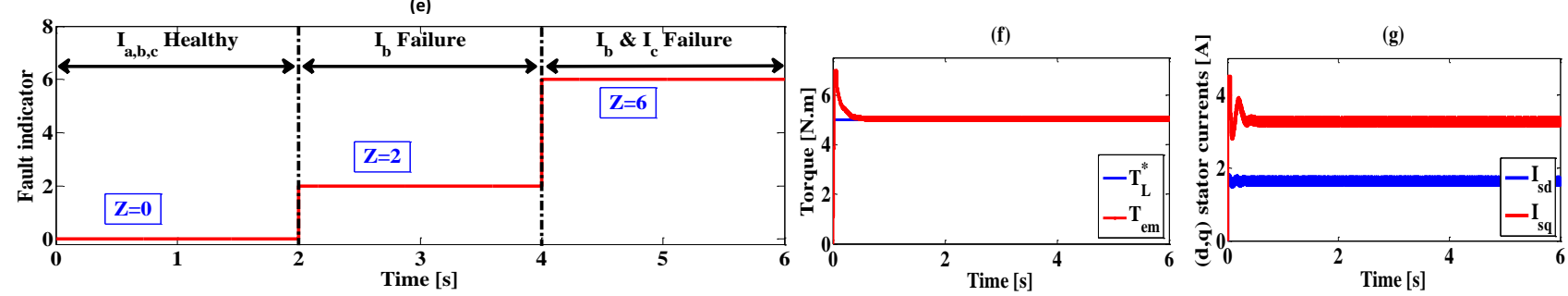

Fig. 9 Simulation results of successive gain faults in sensor-b and sensor-c (sensor-a remains healthy): (a) $I_{a}$ measured and estimated currents, (b) $I_{b}$ measured and estimated currents, (c) $\mathrm{I}_{\mathrm{c}}$ measured and estimated currents, (d) reference and measured speeds, (e) fault indicator, (f) load and electromagnetic torques, (g) direct and quadrature stator currents.
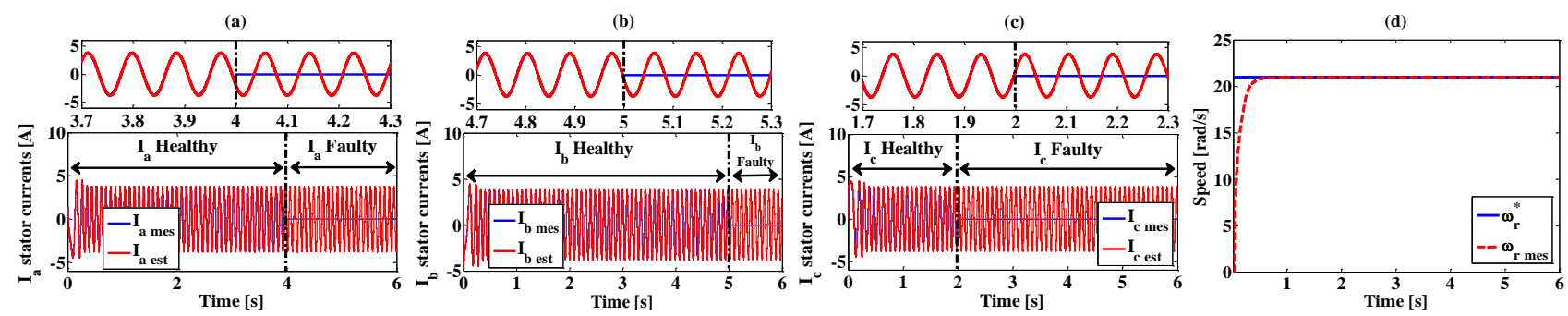
(e)

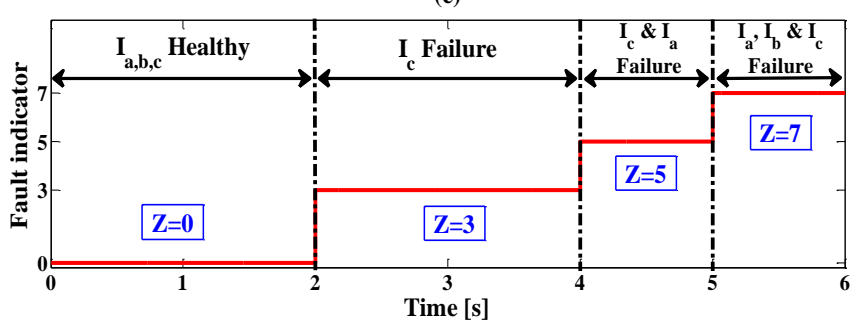

Fig. 10 Simulation results of a complete outage of the three current sensors (sensor-c, sensor-a, and then sensor-b, in succession): (a) $I_{a}$ measured and estimated currents, (b) $I_{b}$ measured and estimated currents, (c) $I_{c}$ measured and estimated current, (d) reference and measured speeds, (e) fault indicator.
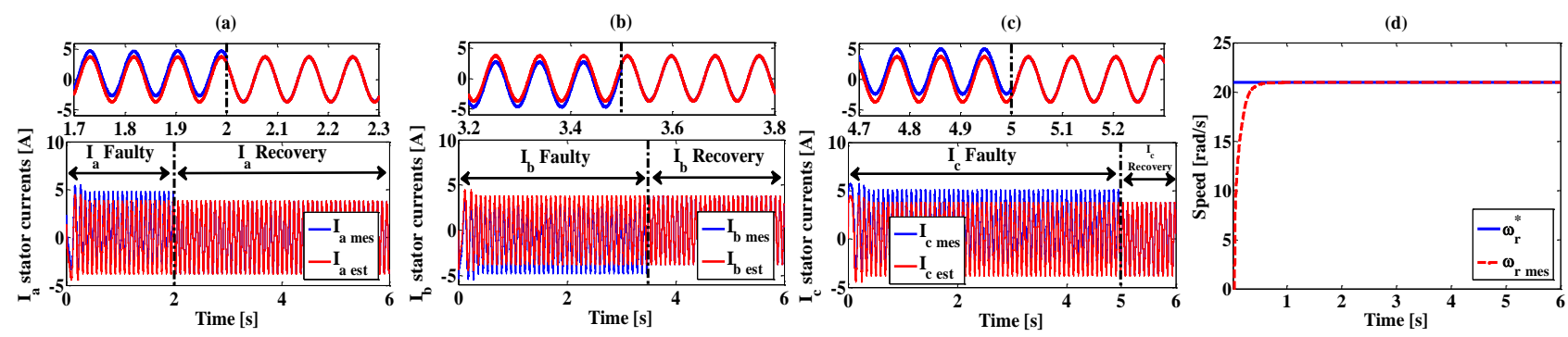

(e)

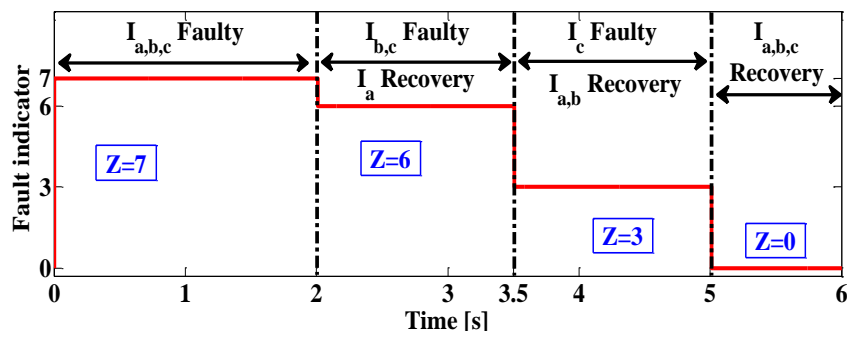

Fig. 11 Simulation results of startup with offset faults in the three current sensors: (a) $I_{a}$ measured and estimated currents, (b) $I_{b}$ measured and estimated currents, (c) $\mathrm{I}_{\mathrm{c}}$ measured and estimated current, (d) reference and measured speeds, (e) fault indicator.

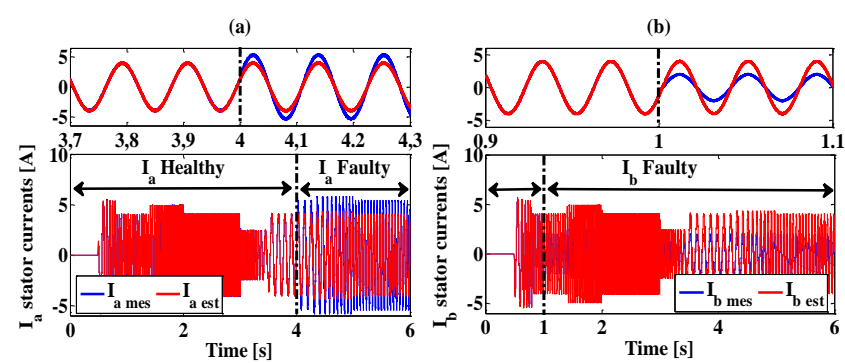

(e)
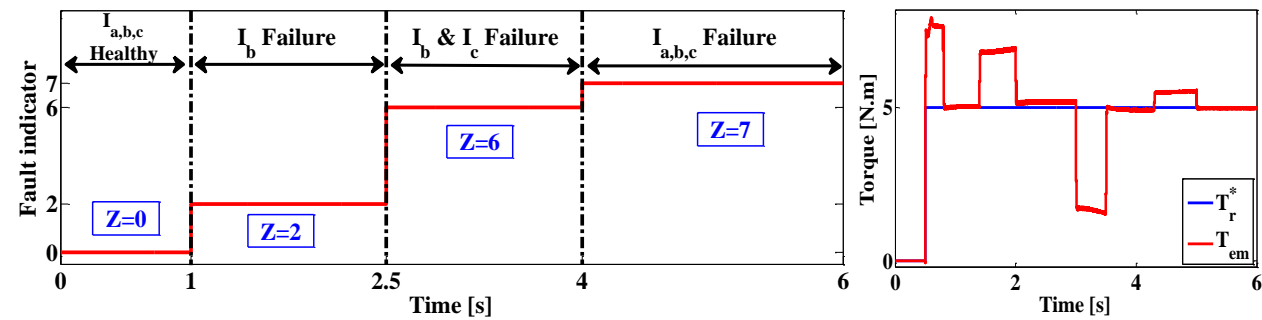

Fig. 12 Simulation results with variable speed and sensor failures: (a) $I_{a}$ measured and estimated currents, (b) $I_{b}$ measured and estimated currents, (c) $I_{c}$ measured and estimated currents, (d) reference and measured speeds, (e) fault indicator, (f) load and electromagnetic torques, (g) direct and quadrature stator currents. 

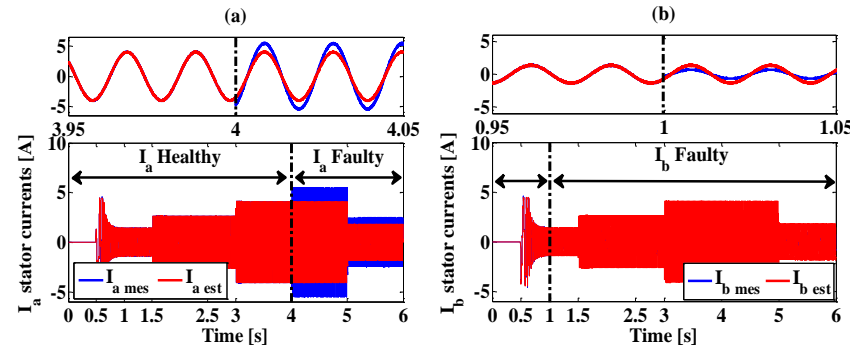

(e)

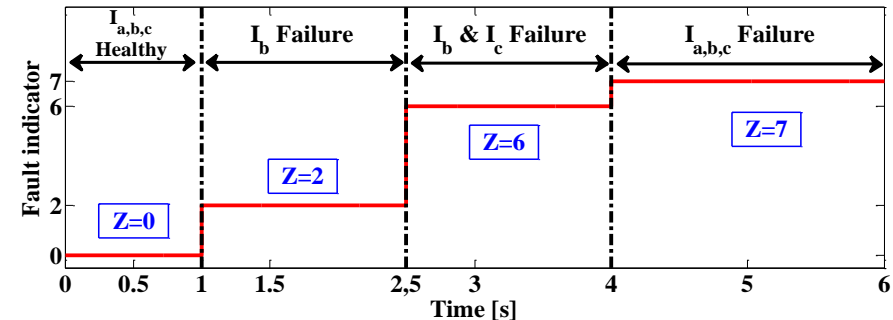

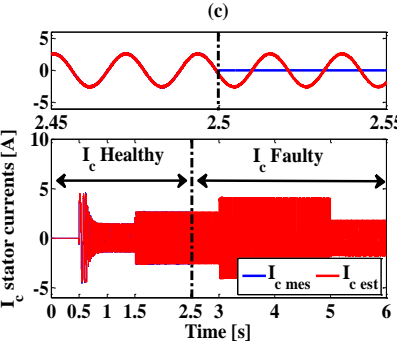

(f)

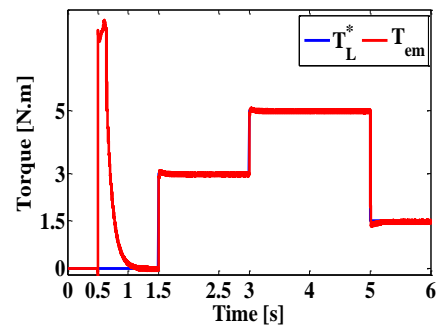

(d)

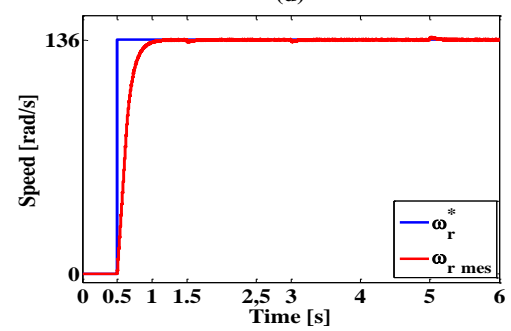

(g)

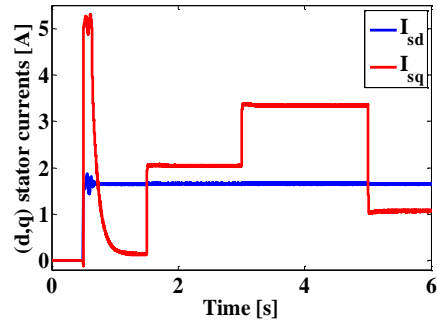

Fig. 13 Simulation results with variable load and sensor failures: (a) $I_{a}$ measured and estimated currents, (b) $I_{b}$ measured and estimated currents, (c) $I_{c}$ measured and estimated currents, (d) reference and measured speeds, (e) fault indicator, (f) load and electromagnetic torques, (g) direct and quadrature stator currents.

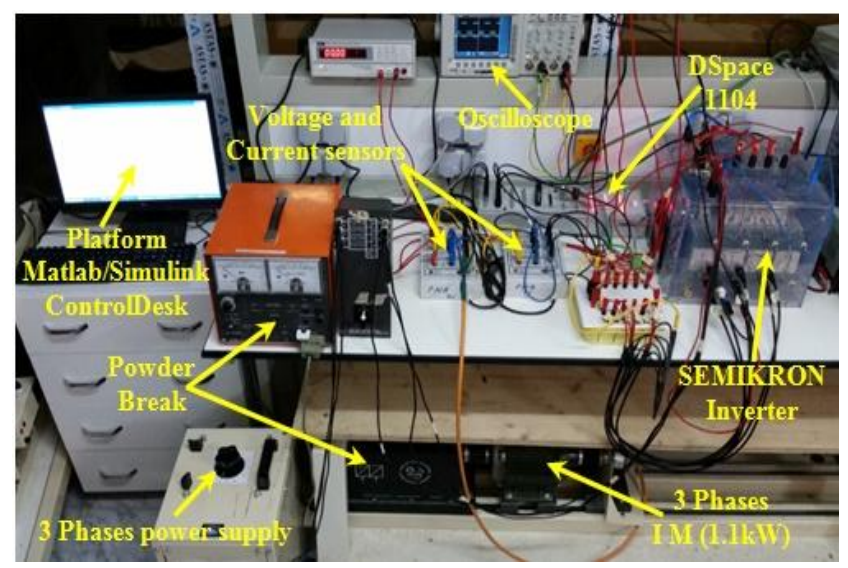

Fig. 14 Experimental test bench.
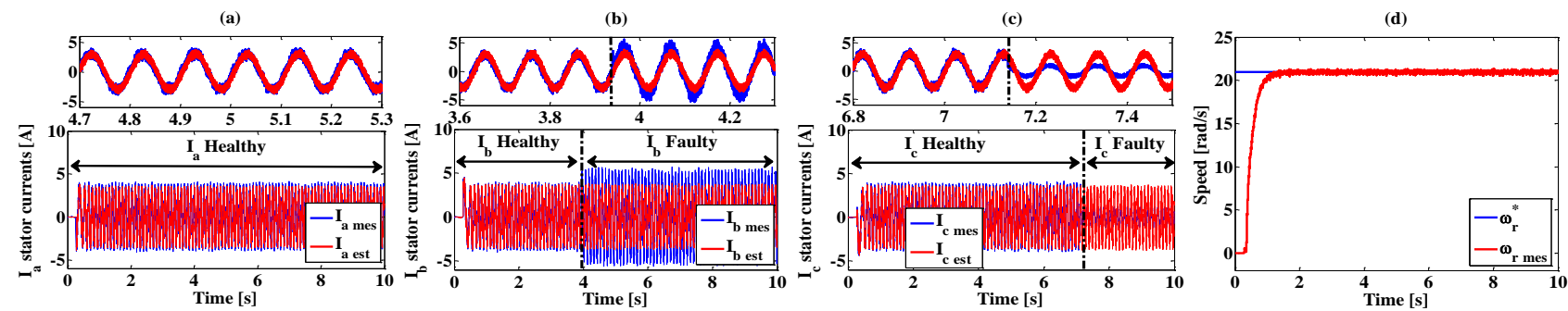

(e)
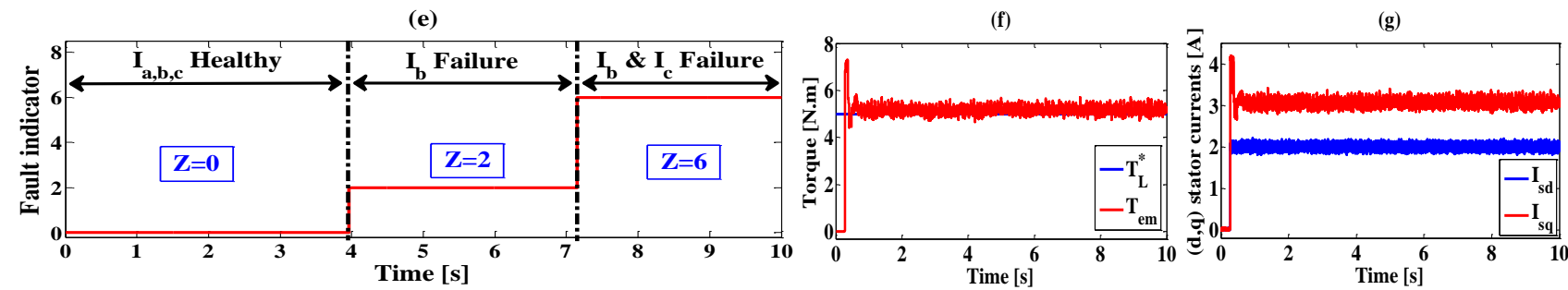

Fig. 15 Experimental results of successive gain faults in sensor-b and sensor-c (sensor-a remains healthy): (a) $\mathrm{I}_{\mathrm{a}}$ measured and estimated currents, (b) $\mathrm{I}_{\mathrm{b}}$ measured and estimated currents, (c) $I_{c}$ measured and estimated current, (d) reference and measured speeds, (e) fault indicator, (f) load and electromagnetic torques, (g) direct and quadrature stator currents. 

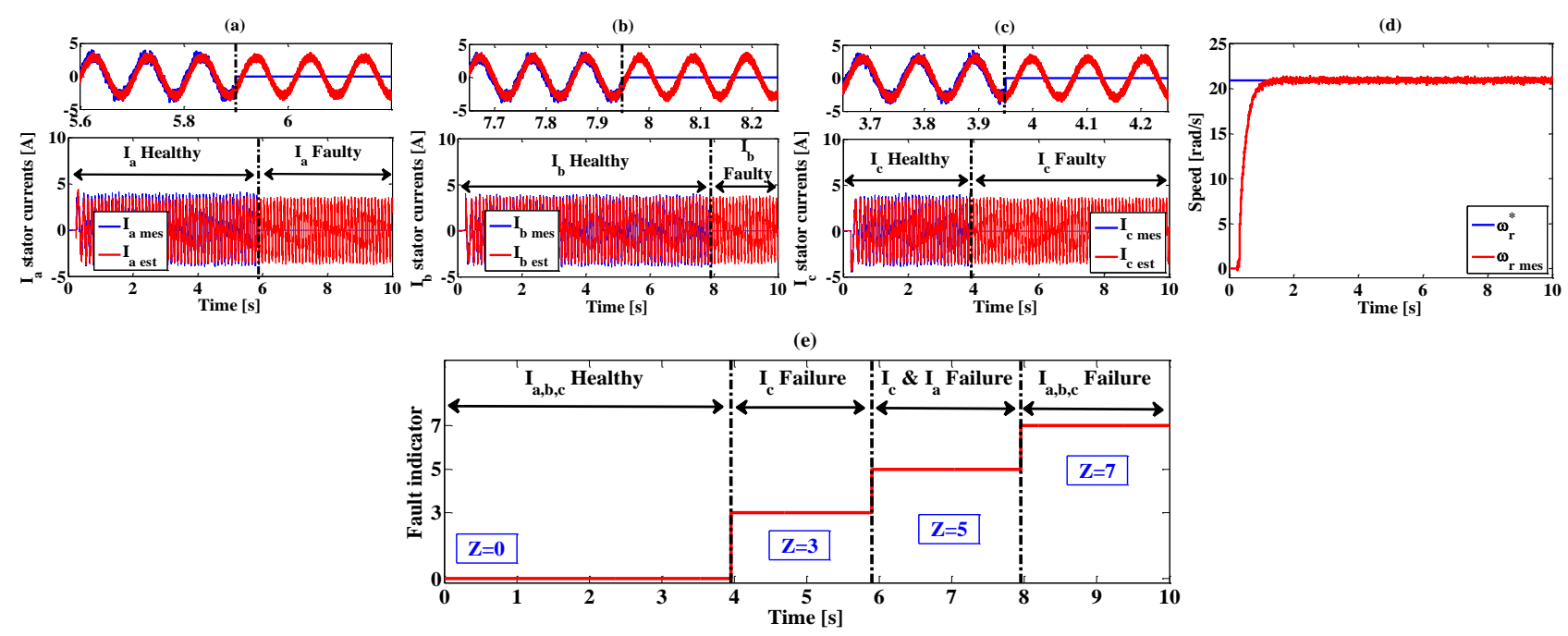

Fig. 16 Experimental results of a complete outage of the three current sensors (sensor-c, sensor-a, and then sensor-b, in succession): (a) $I_{a}$ measured and estimated currents, (b) $\mathrm{I}_{\mathrm{b}}$ measured and estimated currents, (c) $\mathrm{I}_{\mathrm{c}}$ measured and estimated current, (d) reference and measured speeds, (e) fault indicator.
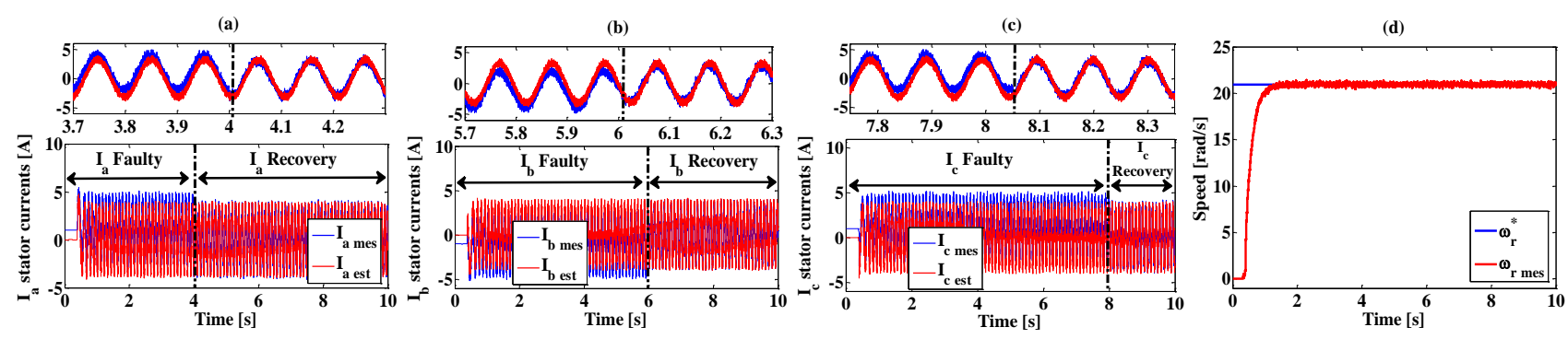

(e)

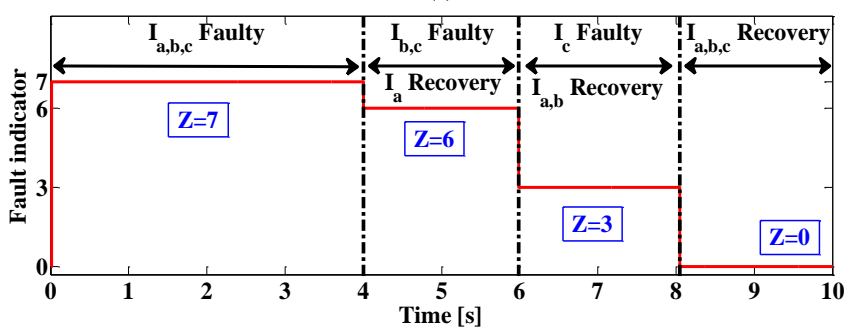

Fig. 17 Experimental results of start-up with offset faults in the three current sensors: (a) $I_{a}$ measured and estimated currents, (b) $I_{b}$ measured and estimated currents, (c) $I_{c}$ measured and estimated current, (d) reference and measured speeds, (e) fault indicator.


(e)

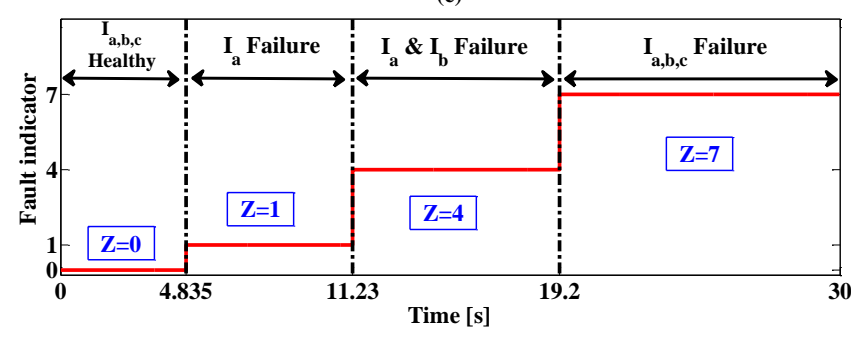

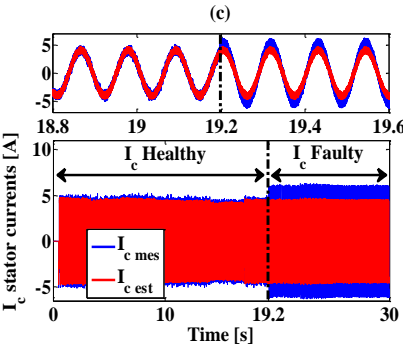

(f)

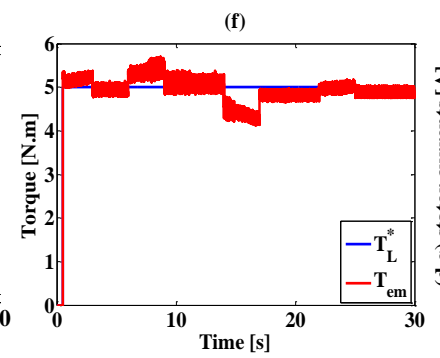

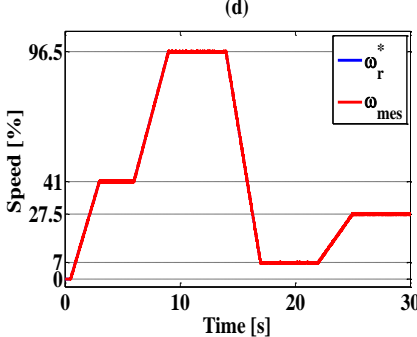

(g)

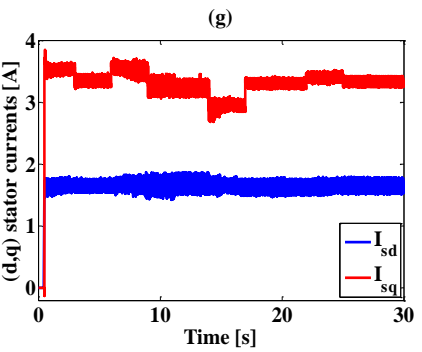

Fig. 18 Experimental results with variable speed and sensor failures: (a) $I_{a}$ measured and estimated currents, (b) $I_{b}$ measured and estimated currents, (c) $I_{c}$ measured and estimated currents, (d) reference and measured speeds, (e) fault indicator, (f) load and electromagnetic torques, (g) direct and quadrature stator currents. 

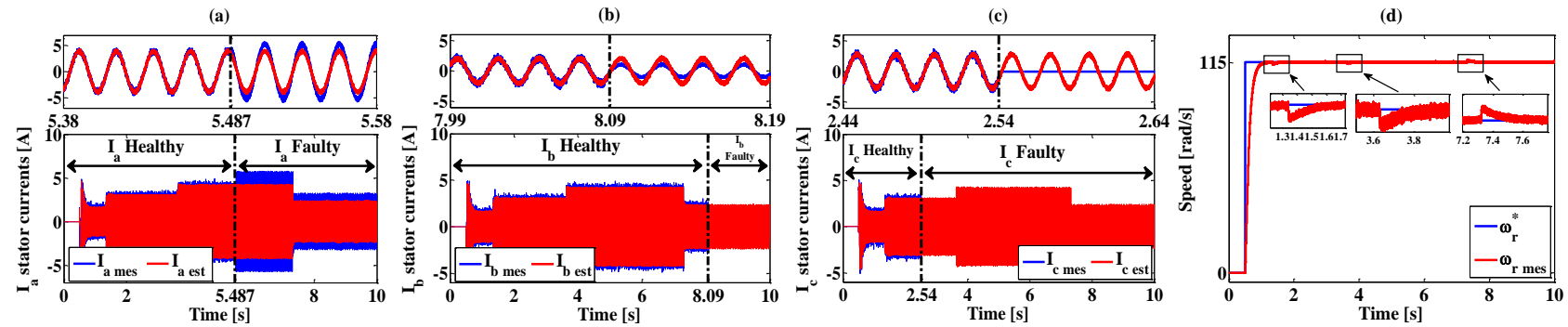

(f)

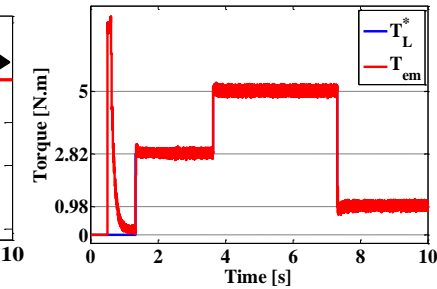

(g)



Fig. 19 Experimental results with variable load and sensor failures: (a) $I_{a}$ measured and estimated currents, (b) $I_{b}$ measured and estimated currents, (c) $I_{c}$ measured and estimated currents, (d) reference and measured speeds, (e) fault indicator, (f) load and electromagnetic torques, (g) direct and quadrature stator currents 